This manuscript has been authored by UT-Battelle, LLC under Contract No. DE-AC0500OR22725 with the U.S. Department of Energy. The United States Government retains and the publisher, by accepting the article for publication, acknowledges that the United States Government retains a non-exclusive, paid-up, irrevocable, world-wide license to publish or reproduce the published form of this manuscript, or allow others to do so, for United States Government purposes. The Department of Energy will provide public access to these results of federally sponsored research in accordance with the DOE Public Access Plan (http://energy.gov/downloads/doe-public-access-plan).

\title{
Advanced Characterization Study of Commercial Conversion and Electrocoating Structures on Magnesium Alloys AZ31B and ZE10A
}

M.P. Brady ${ }^{\mathrm{a}}$, D.N. Leonard ${ }^{\mathrm{a}}$, H.M. Meyer ${ }^{\mathrm{a}}$, III, J.K. Thomson ${ }^{\mathrm{a}}$, K.A. Unocic ${ }^{\mathrm{a}}$, H.H. Elsentriecy ${ }^{\mathrm{a}, \mathrm{b}}$, G.-L. Song ${ }^{\mathrm{a}, \mathrm{d}}$, K. Kitchen ${ }^{\mathrm{c}}$, and B. Davis ${ }^{\mathrm{c}}$

${ }^{a}$ Oak Ridge National Laboratory, Oak Ridge, TN USA

${ }^{\mathrm{b}}$ Central Metallurgical Research \& Development Institute, Cairo, Egypt

${ }^{c}$ Magnesium Elektron North America, Madison, IL USA

${ }^{d}$ now with College of Materials, Xiamen University, Fujian 361005, China

Contact: bradymp@ornl.gov

MS 6156, Oak Ridge National Laboratroy, Oak Ridge, TN USA 37831-6156

TEL: 8655745153

\begin{abstract}
The local metal-coating interface microstructure and chemistry formed on commercial magnesium alloys Mg-3Al-1Zn (AZ31B) and Mg-1Zn-0.25Zr-<0.5Nd (ZE10A, ZEK100 type) were analyzed as-chemical conversion coated with a commercial hexafluoro-titanate/zirconate type + organic polymer based treatment (Bonderite ${ }^{\circledR} 5200$ ) and a commercial hexafluorozirconate type + trivalent chromium $\mathrm{Cr}^{3+}$ type treatment (Surtec ${ }^{\circledR} 650$ ), and after the same conversion coatings followed by electrocoating with an epoxy based coating, Cathoguard® 525 . Characterization techniques included scanning electron microscopy (SEM), x-ray photoelectron spectroscopy (XPS), and cross-section scanning transmission electron microscopy (STEM).
\end{abstract}


Corrosion behavior was assessed in room temperature saturated aqueous $\mathrm{Mg}(\mathrm{OH})_{2}$ solution with 1 wt. $\% \mathrm{NaCl}$. The goal of the effort was to assess the degree to which substrate alloy additions become enriched in the conversion coating, and how the conversion coating was impacted by subsequent electrocoating. Key findings included the enrichment of $\mathrm{Al}$ from AZ31B and $\mathrm{Zr}$ from ZE10A, respectively, into the conversion coating, with moderate corrosion resistance benefits for AZ31B when Al was incorporated. Varying degrees of increased porosity and modification of the initial conversion coating chemistry at the metal-coating interface were observed after electrocoating. These changes were postulated to result in degraded electrocoating protectiveness. These observations highlight the challenges of coating $\mathrm{Mg}$, and the need to tailor electrocoating in light of potential degradation of the initial as-conversion coated Mg alloy surface.

Key Words: magnesium; conversion coating; electrocoating; corrosion; transmission electron microscopy 


\subsection{Introduction}

Magnesium and its alloys are of great interest for engineering applications ranging from functional uses such as biomedical implants to structural alloys to achieve automotive and aircraft vehicle light weighting [1-3]. In vehicle light weighting applications, the rapid corrosion of $\mathrm{Mg}$, particularly when exposed to salt species under aqueous conditions, is a key issue [4-16]. Alloying generally results in only moderate improvement in the aqueous corrosion resistance of Mg. Therefore, coatings are typically used to provide corrosion protection for $\mathrm{Mg}$ components [17-21].

Coatings for $\mathrm{Mg}$ structural components generally utilize a multi-layer strategy, involving an initial cleaning step; a surface pre-treatment such as chemical or electrochemical conversion coatings, surface alloying, anodization, etc.; a second coating layer such as electrocoatings, platings, powder coatings, organic coatings, etc.; frequently followed by a final layer of sealant and/or paint [17-41]. In single- and multi-layer coating concepts, the interface between the substrate alloy and the initial coating layer is critical to coating adherence and performance. Delamination or through attack in this region can allow the environment to access the underlying alloy and result in local corrosion and coating failure.

Chemical conversion coatings are frequently used industrially as the first coating step after surface cleaning due to their relatively low cost and ease of implementation $[17,19,29,30,33$, 38]. They are primarily used to provide a receptive surface for subsequent coating layer step adherence, but can also contribute to overall corrosion resistance of the multi-layer coating system $[17,19,23,26]$. Chromate conversion coatings provide the basis for good protection of 
$\mathrm{Mg}$ alloys, but result in significant safety and environmental issues related to hexavalent $\mathrm{Cr}, \mathrm{Cr}^{6+}$ $[17,19]$. Alternatives to chromate conversion coatings for $\mathrm{Mg}$ alloys include phosphatepermanganates, fluorides, stannates, organics, vanadates, and rare earths [17, 19].

Conversion coatings for $\mathrm{Mg}$ alloys have been the subject of intense study [e.g. reviews in references 17, 19]. Much of this work has emphasized coating processing development and subsequent corrosion resistance assessment. However, relatively few studies have pursued advanced microstructural characterization of the local chemistry, morphology, and structure of the coating and coating/substrate interface, e.g. for $\mathrm{Mg}$ substrates [42, 43] and for Al substrates 44-46]. Such understanding is of particular importance for conversion coatings, as the resultant surface and its corrosion resistance are influenced not only by the coating solution chemistry and process conditions, but also by the substrate $\mathrm{Mg}$ alloy composition and microstructure [17, 19, 40].

The goal of the present work was to characterize the chemistry and morphology of several stateof-the-art $\mathrm{Cr}^{6+}$ free commercial conversion coatings for two representative $\mathrm{Mg}$ alloys of different composition classes using standard process conditions, and then after subsequent application of a commercial, state-of-the-art electrocoating. Such electrocoatings are one approach under consideration as the next protective layer above the conversion coating in multi-layered coating schemes used to protect Mg alloys [e.g. 22, 23]. Conversion coatings and/or electrocoatings have been developed and successfully used to protect steels and aluminum, but are less well established for Mg alloys. Detailed knowledge of the chemistry and structure at the metal- 
coating interface as-conversion coated and after electrocoating is needed to provide baseline understanding for future coating development and optimization to protect $\mathrm{Mg}$ alloys.

\subsection{Materials and Methods}

Two substrate alloys relevant to automotive applications were selected for study, $\mathrm{AZ31B}$, a Mg3Al-1Zn type, and Elektron ${ }^{\circledR} 717$ (E717 for brevity), a ZE10A type rare earth and Zr modified Mg- $1 \mathrm{Zn}-0.25 \mathrm{Zr}-<0.5 \mathrm{Nd}$. These alloys are both near-single-phase, but do contain second phase Al-Mn (AZ31B) and Zn-Zr/Nd rich (E717) intermetallic second phases [16, 47-49]. The alloy test samples were electro-discharged machine (EDM) cut from wrought coil sheet $\sim 1.5-1.6 \mathrm{~mm}$ thick obtained from Magnesium Elektron North America (MENA), Madison, IL USA. The E717 is of particular interest for automotive applications as it was recently demonstrated to be amenable to warm forming of door panels [50]. Analyzed compositions are shown in Table 1 [16]. (It should be noted that some scatter in the range of Fe impurity level was found in the E717 sheet material [16]. Data for Fe levels from 2 different measurements for AZ31B and 3 different measurements for E717 are shown in Table 1. Note that the test samples were polished to remove all residual surface finish prior to compositional analysis, as steel processing rolls can impart Fe impurities to the sheet surface during manufacture [16]. Such surface contamination does not appear to be the source of the variation in Fe level detected for the E717 sheet [16]).

Table 1. Alloy chemical composition of AZ31B and E717 sheet determined by inductively coupled plasma atomic emission spectroscopy (ICP-AES) [after reference 16]. The E717 contains $<0.5 \mathrm{wt} . \% \mathrm{Nd}$, the exact level of $\mathrm{Nd}$ is considered proprietary.

\begin{tabular}{c|c|c|c|c|c|c|c|c|c}
\hline \multirow{2}{*}{ Alloy } & \multicolumn{10}{|c}{ Composition weight \% (wt.\%) } \\
\cline { 2 - 10 } & $\mathrm{Mg}$ & $\mathrm{Al}$ & $\mathrm{Zn}$ & $\mathrm{Zr}$ & $\mathrm{Mn}$ & $\mathrm{Nd}$ & $\mathrm{Fe}$ & $\mathrm{Cu}$ & $\mathrm{Ni}$ \\
\hline $\begin{array}{c}\text { AZ31B } \\
\text { sheet }\end{array}$ & 95.47 & 3.05 & 1.00 & $<0.001$ & 0.46 & $<0.001$ & $\begin{array}{c}0.001, \\
0.002\end{array}$ & 0.001 & 0.001 \\
\hline $\begin{array}{c}\text { E717 } \\
\text { sheet }\end{array}$ & $\mathrm{Bal}$. & 0.004 & 1.49 & 0.31 & 0.008 & $<0.5$ & $\begin{array}{c}0.0007, \\
0.007,\end{array}$ & 0.001 & 0.001 \\
\hline
\end{tabular}




\begin{tabular}{l|l|l|l|l|l|l|l|l|l}
\hline & & & & & & & 0.008 & & \\
\hline
\end{tabular}

Bare (uncoated) AZ31B and E717 for corrosion studies were prepared as $15 \mathrm{~mm}$ diameter disks to a 1200 grit surface finish by wet grinding with $\mathrm{SiC}$ paper (Buehler, 41 Waukegan Road, Lake Bluff, Illinois 60044 USA), cleaned with acetone and deionized water, and dried with an air stream. Samples were then stored in a desiccator for at least $24 \mathrm{~h}$ prior to the corrosion exposures. Samples for coating were EDM cut to $15 \mathrm{~mm}$ diameter disks or $25 \mathrm{~mm}$ x $25 \mathrm{~mm}$ squares from the as-received sheet (no surface grinding). Two commercially available, state-ofthe-art conversion coatings were selected for study: Bonderite ${ }^{\circledR} 5200$ (chromium free hexafluoro-titanate/zirconate type + organic polymer based $[26,28,45,51]$, (Henkel Corporation, North America, One Henkel Way, Rocky Hill, CT 06067 USA) and Surtec ${ }^{\circ} 650$ (hexofluoro-zirconate type with addition of trivalent chromium $\mathrm{Cr}^{3+}$ [46], (Surtec International, Neuhofstraße 9 , 64625 Bensheim Germany). Additional coated samples were made after the same conversion coating treatments followed by electrocoating with Cathoguard ${ }^{\circledR} 525$ (epoxy based) (BASF Corporation 26701 Telegraph Rd.Southfield, MI 48033 USA).

The conversion coatings were processed for AZ31B and E717 substrates by MENA, and by a commercial vendor for the subsequent electrocoat layer according to standard industry practices. The test samples for coating were in the as-mill received sheet state. Surfaces for conversion coating were prepared by cleaning in $10 \%$ nitric acid, followed by purified water rinse. The Bonderite ${ }^{\circledR} 5200$ treatment was prepared using the commercially procured coating solution, diluted to $5 \%$ as directed, with sample immersion for 2 minutes at $\sim 21^{\circ} \mathrm{C}$, purified water rinsed, and air dried. The Surtec ${ }^{\circledR} 650$ treatment was prepared using the commercially procured 
coating solution, diluted to $20 \%$ as directed, with sample immersion for 1 minute $21^{\circ} \mathrm{C}$, purified water rinsed, and air dried. Additional AZ31B and E717 test samples were first conversion coated in the same manner and then electrocoated with Cathoguard ${ }^{\circledR}$ 525. The Cathoguard $\AA$ 525 electrocoat was processed by a commercial vendor in the same manner for as-conversion coated AZ31B and E717 substrates, in the specified process window of bath temperature of 32$36^{\circ} \mathrm{C}, \geq 2$ minutes coating, $100-400 \mathrm{~V}$, followed by $\sim 175^{\circ} \mathrm{C}$ curing for $\sim 20$ min. For brevity, the Bonderite ${ }^{\circledR} 5200$ coatings are referred to as BAZ (on AZ31B) or BE7 (on E717), Surtec ${ }^{\circledR} 650$ as SAZ and SE7, and Cathoguard ${ }^{8} 525$ as electrocoat, e.g. BAZ + electrocoat, etc.

Coated samples were characterized by surface and cross-section scanning electron microscopy (SEM) with energy dispersive x-ray analysis (EDS), x-ray photoelectron spectroscopy (XPS) (as conversion coated surfaces only), and cross-section scanning transmission electron microscopy (STEM). The XPS analysis used a monochromated, micro-focusing, Al Ka X-ray source (1486.6 $\mathrm{eV}$ ) with a $\sim 400 \mu \mathrm{m}$ X-ray spot size for maximum signal and to obtain an average surface composition over the largest possible area [49]. Depth profiling analyses were conducted with a Thermo Scientific EX06 argon ion gun operated at $1000 \mathrm{eV}$ and rastered over a $2 \mathrm{~mm}$ x $4 \mathrm{~mm}$ area [49]. The specimens for STEM analysis were prepared via the focus ion beam (FIB) milling technique by the in-situ lift-out method using a Hitachi NB5000 FIB-SEM [49]. A tungsten and/or carbon and tungsten overlayer was deposited to protect the exposed top surface of the film during ion milling. Further details of the sample preparation and analysis methodology are provided elsewhere [49]. 
Corrosion evaluation for bare, as conversion coated, and conversion coated + electrocoated AZ31B and E717 samples was conducted at room temperature $\left(\sim 21^{\circ} \mathrm{C}\right)$ in aqueous saturated $\mathrm{Mg}(\mathrm{OH})_{2}$ solution with 1 wt. $\% \mathrm{NaCl}$. Test samples were $15 \mathrm{~mm}$ diameter disks sealed inside a polytetrafluoro- ethylene (PTFE) cell with single face exposed through a $1.00 \mathrm{~cm}^{2}$ circular window. The counter electrode was a 2 x $2 \mathrm{~cm} \mathrm{Pt}$ flag, and the reference electrode was $\mathrm{Ag} / \mathrm{AgCl}$ (nominal $4 \mathrm{M} \mathrm{KCl}$ internal solution). Experiments were conducted with a model PARSTAT 4000, Potentiostat/Galvanostat/EIS Analyzer (Princeton Applied Research). The bare and asconversion coated samples were equilibrated in solution for $30 \mathrm{~min}$. before test initiation. Potentiodynamic polarization scans were taken from $\sim-1.8 \mathrm{~V}$ to $\sim-0.9 \mathrm{~V}$ (approximately $-0.3 \mathrm{~V}$ vs open circuit potential (OCP) to $+0.6 \mathrm{~V}$ vs. $\mathrm{OCP}$ ) using a scan rate of $0.166 \mathrm{mV} / \mathrm{s}$. The conversion coated + electrocoated samples were not initially conductive due to the insulating nature of the epoxy-based electrocoat. They were loaded in the PTFE sample holder and immersed in the saturated $\mathrm{Mg}(\mathrm{OH})_{2}$ solution with $1 \mathrm{wt} . \% \mathrm{NaCl}$, with electrochemical impedance spectroscopy (EIS) measurements taken at $0,8,16,24,32,40$, and $48 \mathrm{~h}$ of exposure. After the final EIS measurement at $48 \mathrm{~h}$, a polarization scan was taken from approximately $-1.75 \mathrm{~V}$ to $\sim$ $0.9 \mathrm{~V}$ vs $\mathrm{Ag} / \mathrm{AgCl}$ (start/finish voltage ranges varied sample run to sample run by $\sim \pm 0.1 \mathrm{~V}$ ) to conclude the test. At least two samples were run for each alloy substrate/coating combination.

\subsection{Results}

\subsection{SEM and XPS Analysis of As-Conversion Coated Surfaces}

SEM images of as-conversion coated surfaces are shown in Fig. 1. The surfaces formed on the AZ31B with both conversion coats appeared qualitatively coarser/rougher with more local surface cracking than on the E717 surfaces. It should be noted that cracking in Mg-based films 
has been attributed to Pilling-Bedworth Ratio effects, with $\mathrm{Mg} / \mathrm{MgO}<1$ resulting in local film cracking; volume expansion cracking from the $\mathrm{MgO}$ to $\mathrm{Mg}(\mathrm{OH})_{2}$ transformation; and artifacts exacerbated by exposure to vacuum during electron microscopy resulting in dehydration "mud" cracking [49]. The relative contribution of these effects was not evaluated in the present work, although the absence of uniform, widespread cracking suggests that vacuum dehydration may not be the dominant factor.

Analysis by EDS indicated that $\mathrm{O}, \mathrm{C}$, and $\mathrm{F}$ were detected for all of the conversion coated surfaces. For BAZ and BE7 surfaces Al, Si, Ti, and Zr were also detected, whereas for $\mathrm{SAZ} \mathrm{Al,}$ $\mathrm{Si}, \mathrm{Cr}$, and $\mathrm{Zr}$ and SE7 Si, Cr, and $\mathrm{Zr}$ were detected. Second phase particles rich in Al-Mn were observed on the conversion coated AZ31B surfaces (Fig. 1 a, c), and Zr-rich particles on the conversion coated E717 (Fig. 1 b, d), consistent with the reported alloy second phase microstructures $[16,47-49]$.

Analysis by XPS (Fig. 2) indicated that the BAZ and BE7 surfaces contained higher levels of C (consistent with an organic binder, Figs. 2 a, b), that were present to far greater depths on sputtering than the SAZ and SE7 surfaces. All surfaces were also rich in $\mathrm{O}$ and $\mathrm{Mg}$, with $\mathrm{F}$ detected as well at lesser levels. Consistent with their conversion coating additives, the BAZ and BE7 surfaces were rich in $\mathrm{Ti}$, and to a lesser extent $\mathrm{Zr}$, whereas the SAZ and SE7 surfaces were rich in $\mathrm{Zr}$, and to a lesser extent $\mathrm{Cr}$. Minor amounts of $\mathrm{N}$ (up to a few at.\%) were also detected in the BAZ and BE7 surfaces but not the SAZ and SE7, which instead showed up to 1 at.\% range $\mathrm{S}$ (neither $\mathrm{N}$ nor $\mathrm{S}$ were presented in Fig. 2 profiles because their levels were so low). In the conversion coated AZ31B surfaces (BAZ and SAZ, Figs. 2 a, c), Al was detected, with 
somewhat higher levels for BAZ than for the SAZ (Figs. 2a, c). For the conversion coated E717 surfaces (BE7 and SE7, Figs $2 \mathrm{~b}, \mathrm{~d}$ ), the levels of Zr detected were higher than on the AZ31B (Figs. 2 a, c). (Relative XPS measurement values estimated to be within 1-2 at.\%). Of relevance to these observations, the AZ31B alloy contains $\mathrm{Al}$ and the E717 contains $\mathrm{Zr}$ (Table 1).

\subsection{SEM Analysis of As-Conversion Coated and Conversion Coated + Electrocoated Cross-}

\section{Sections}

Cross-section SEM images of the as-conversion coated AZ31B and E717 are shown in Fig. 3. The BAZ and BE7 coatings were moderately thicker, $\sim 0.6$ to 1 microns, than those for the SAZ and SE7, $\sim 0.4$ to 0.6 microns, on both substrate alloys. Occasional through-cracks were observed in the BAZ coating (Fig. 3a). Similar cracks were not observed in the BE7 coating; however, the BE7 coating appeared more porous (Fig. 3b). Then SAZ and SE7 coatings had a dense appearance, but with occasional local thin areas where local coverage of the surface was not as complete.

SEM cross-section images and elemental maps (by EDS) for the conversion coated + electrocoated AZ31B and E717 are shown in Figs. 4-7. The outer electrocoat layer was on the order of 10 microns thick on the BAZ, BE7, and SAZ conversion coated surfaces. A thinner electrocoat layer, on the order of 5 microns thick, was formed on the SE7. Elemental mapping indicated that the epoxy electrocoat contained irregular sized and shaped oxide particles rich in Al Si, Mo, and/or Ti. 
The morphology of the original metal-conversion coated interface was impacted by the electrocoat process employed. For BAZ (Fig. 4) and SE7 (Fig. 7), thin, distinct, and laminar interfacial structures were retained from the original metal-conversion coat interface after electrocoating, although in the case of BAZ through cracks were also observed (more prevalent than in as-conversion coated, Fig. 3a). In contrast, a thicker and rougher interface was observed at the original metal-conversion coat interface for BE7 (Fig. 5), where local voiding was also observed, and, in particular, SAZ which also revealed through cracking at the metal interface (Fig. 6).

Elemental mapping for the electrocoated BAZ and SE7, which formed the laminar interfacial structure with the metal substrate (Figs. 4 and 7), revealed element enrichment at the metalcoating interface as continuous layers. In $\mathrm{BAZ}+$ electrocoat, $\mathrm{O}, \mathrm{F}, \mathrm{Mg}$, and $\mathrm{Al}$ were continuous and suggestive of a Mg-O-F compound intermixed with oxidized Al at the metal interface (Fig. 4). Semi-continuous $\mathrm{Zr}$ and $\mathrm{Ti}$ associated with oxygen were observed just above the F-rich layer. Similar continuous $\mathrm{O}, \mathrm{F}$, and $\mathrm{Mg}$ were observed at the metal interface in SE7 (no $\mathrm{Al}$ ), along with $\mathrm{Zr}, \mathrm{Zn}$, and $\mathrm{P}$ (Fig. 7). (The P observed in SE7+ electrocoat was surprising as it was not observed in any other electrocoat sample by SEM and STEM, and was not detected in the initial as-conversion coated surface by XPS. An artifact such as a peak overlap in EDS mapping is suspected, $\mathrm{Zr}$ being the most likely possibility).

In contrast, the chemistry of the rougher metal-coating interface observed in electrocoated BE7 and SAZ (Figs. 5, 6) showed much less distinct element enrichment. In both cases, the rough metal interface regions were associated with oxidized $\mathrm{Mg}$ (i.e. the electrocoating process 
attacked the initial as-conversion coated surface). Enrichment of $\mathrm{F}$ to the metal-interface region was much less distinct in BE7 + electrocoat (Fig. 5), and essentially absent in the SAZ + electrocoat (Fig. 6). Patchy regions of $\mathrm{Zr}$ and Ti were observed in BE7+ electrocoat at the metal interface region, but were absent for SAZ + electrocoat.

\subsection{STEM Analysis of As-Conversion Coated and Conversion Coated + Electrocoated Cross-}

\section{Sections}

To gain further insight into the chemistry of the metal interface as conversion coated, and after electrocoating, cross-section STEM analysis was pursued. In Figures 8-11, (a) shows asconversion coated and (b) shows conversion coated + electrocoat cross-sections for each of the 4 alloy substrate/conversion coating combinations studied before/after electrocoat.

The coating region imaged for BAZ (Fig. 8a) was locally discontinuous with several large voids (largest dimension on order of 0.5 microns), indicating a local region of poor conversion coating coverage, but still showed very distinct $\mathrm{F}$ and $\mathrm{Mg}$ enrichment. Oxygen was observed above the $\mathrm{F}$ layer, but was diffuse, with little evidence of $\mathrm{Al}, \mathrm{Ti}$, or $\mathrm{Zr}$ enrichment at this location. However, the sample region imaged after electrocoating (Fig. 8b) showed distinct elemental enrichment at the metal interface, more consistent with features observed by SEM (Fig. 4). (This suggests that the as-conversion coated region imaged in Fig. 8a may not have been representative of the majority of the coating structure). The BAZ + electrocoat region imaged (Fig. 8b) showed a distinct inner F rich layer associated with $\mathrm{Mg}$, above which a porous oxide layer also associated with $\mathrm{Mg}$ was observed. Aluminum, and to a lesser extent $\mathrm{Zn}$, was present throughout the interfacial coating region between metal and epoxy electrocoat, both in the inner F-rich layer and 
outer O-rich zone. Ti was strongly enriched near the interface between the F- and O- rich layers, possibly associated with $\mathrm{N}$ ( $\mathrm{N}$ map was indistinct). $\mathrm{Zr}$ was detected in the O-rich zone, but the map was quite diffuse.

In contrast, the BE7 (Fig. 9a) showed continuous and distinct elemental enrichment, but that structure was significantly disrupted after electrocoating (Fig. 9b). As-conversion coated BE7 showed a dense, continuous inner layer composed of $\mathrm{O}, \mathrm{F}$, and $\mathrm{N}$, rich in $\mathrm{Mg}$, $\mathrm{Ti}$, and to a lesser extent $\mathrm{Zr}$ and $\mathrm{Zn}$. Consistent with the SEM cross-section (Fig 3b), the outer region of the asconversion coated structure (Fig. 9a) was porous with a fibrous-like structure reminiscent in morphology of outer fiber/platelet $\mathrm{Mg}(\mathrm{OH})_{2}$ structures typically observed in aqueous corrosion films formed by $\mathrm{Mg}$ alloys [16, 49]. After electrocoating (Fig. 9b), the original conversion coating region became less laminar and more porous and diffuse, and was extensively intermixed with the electrocoat, which in some regions (Figs. 5 and 9b) undercut the original conversion coated layer at the metal interface. Elemental mapping showed a thin, continuous region rich in $\mathrm{Mg}, \mathrm{F}$, and Ti remnant at the coating-metal interface, but with more diffuse distribution of $\mathrm{O}, \mathrm{Zr}$, $\mathrm{Mg}$, and Ti in the prior conversion-coated structure intermixed with the electrocoat.

Figures 10 and 11 show the STEM cross-section images for the SAZ and SE7 conversion coatings before and after electrocoating. On the AZ31B (Fig. 10a), the SAZ as-conversion coated structure was thin and relatively dense, with the inner regions near the metal interface rich in $\mathrm{Mg}$, $\mathrm{O}, \mathrm{F}$, and $\mathrm{Al}$, and the outer regions also containing a patchy, semi-continuous $\mathrm{Zr}$ and $\mathrm{Cr}$ rich region. After electrocoating (Fig. 10b), consistent with the SEM cross-section (Fig 6), the metalcoating interfacial region was more diffuse and extensively oxidized. The oxide was rich in $\mathrm{Mg}$, 
with patchy areas also containing $\mathrm{Al}$ and $\mathrm{Zn}$. Distinct regions with $\mathrm{Cr}, \mathrm{Zr}$, or $\mathrm{F}$ were no longer observed.

On the E717 (Fig. 11a), the SE7 conversion coating yielded a laminar, duplex structure, with an inner, continuous, dense region rich in $\mathrm{Mg}$ and $\mathrm{F}$, and an outer, more diffusive region with occasional voids rich in $\mathrm{O}, \mathrm{Cr}, \mathrm{Zr}$, and $\mathrm{Zn}$. After electrocoating, a continuous, distinct layer remained at the metal interface; however, it contained a large fraction of fine voids (Fig. 11b). Elemental mapping indicated this voided layer was rich in $\mathrm{Mg}, \mathrm{Zn}$, and $\mathrm{O}$, with diffuse presence of $\mathrm{F}$ and $\mathrm{Al}$ also observed.

\subsection{Corrosion Behavior}

Corrosion behavior of bare and as-conversion coated alloys was evaluated by potentiodynamic polarization in aqueous saturated $\mathrm{Mg}(\mathrm{OH})_{2}$ with 1 wt.\% $\mathrm{NaCl}$. The bare (uncoated) AZ31B and E717 alloys exhibited similar, relatively repeatable potentiodynamic polarization behavior (to simplify Fig. 12, only 1 curve of 2 different samples tested for each alloy is presented). The primary difference in the response of the two bare alloys was a modestly higher open circuit potential (OCP) for the AZ31B than for the E717 ( -1.45V vs. -1.55 V) (Fig. 12).

Some sample-to-sample scatter was observed in the corrosion response for the conversion coated alloys, consistent with the microstructural and chemical coating variation observed in SEM and STEM analysis. Therefore, two to three samples were run for each conversion coating-alloy combination, with the best and worst performing samples shown in Fig. 12. The BAZ 
conversion coating had a beneficial effect on the AZ31B (Fig. 12a), increasing the OCP from $1.45 \mathrm{~V}$ to $\sim-1.35$ to $-1.25 \mathrm{~V}$, with one run (BAZ-1) also exhibiting a partial degree of passive-like behavior up to near $-1 \mathrm{~V}$. On the E717 substrate (BE7, Fig. 12b) only a minor effect (BE7-2 showed a small, local partially passive region) of the conversion coating on the potentiodynamic polarization behavior relative to bare (uncoated) E717 was observed. With the SAZ conversion coating there was a minor increase in OCP for AZ31B ( - $1.4 \mathrm{~V}$ vs. $-1.45 \mathrm{~V}$ for the bare alloy) (Fig. 12c), and essentially no change was observed conversion coated vs. the bare alloy for the E717 (SE7, Fig. 12d). It should be noted that conversion coatings alone are not sufficient to afford good corrosion protection for $\mathrm{Mg}$ alloys immersed in salt solutions, they primarily provide a suitable surface for subsequent coating layers [17-19]. However, as-conversion coated alloy corrosion was studied because the conversion coatings may also contribute to the overall corrosion resistance of the multi-layer coating system strategies employed to protect $\mathrm{Mg}$ alloys $[17,19]$.

The epoxy-based electrocoatings were insulating, and therefore not amenable for initial study by potentiodynamic polarization. They were immersed for $48 \mathrm{~h}$ in the saturated $\operatorname{Mg}(\mathrm{OH})_{2}$ with 1 wt.\% $\mathrm{NaCl}$ test solution (which is an aggressive corrosion screening condition), during which EIS measurements were taken at $0,8,16,24,32,40$, and $48 \mathrm{~h}$ of immersion, followed by a single potentiodynamic polarization scan of $\sim-1.75 \mathrm{~V}$ to $\sim-0.9 \mathrm{~V}$ vs. $\mathrm{Ag} / \mathrm{AgCl}$ after the $48 \mathrm{~h}$ immersion. Photographs of the conversion coated + electrocoated test samples after this corrosion test protocol are shown in Fig.13. The duplicate electrocoated BAZ and BE7 samples experienced significant variation in electrocoating protectiveness, with near complete loss of the electrocoating in one of the two duplicate runs made (Fig. 13 a, b). Both electrocoated SAZ 
samples experienced extensive corrosion, with disintegration of the underlying alloy (Fig 13c).

The electrocoated SE7 exhibited qualitatively better and more consistent corrosion resistance for the two samples run, although pitting degradation of the electrocoating surface was still observed (Fig. 13d). Overall, these findings indicate that all of the electrocoatings contained defects, which resulted in sample-to-sample corrosion variation of an extent that the associated electrochemical EIS/potentiodynamic data were not sufficiently reproducible to permit comparative analysis (and a therefore not presented).

\subsection{Discussion}

A summary of key findings from SEM, XPS, and STEM analysis for as-conversion coated and conversion coated + electrocoated microstructures for AZ31B and E717, along with subsequent corrosion behavior for as-conversion coated alloys is provided in Table 2.

Table 2- Summary of key observations from microstructure analysis and potentiodynamic polarization studies in saturated $\mathrm{Mg}(\mathrm{OH})_{2}+1$ wt.\% NaCl. Corrosion resistance key: "=" means comparable to bare (uncoated) alloy, ">" means better than bare alloy.

\begin{tabular}{|c|c|c|}
\hline Coating & AZ31B & E717 \\
\hline $\begin{array}{l}\text { Bonderite } \AA 5200 \text { (primarily } \\
\text { adds } \mathrm{O}, \mathrm{C}, \mathrm{Ti}, \mathrm{F}, \mathrm{Zr} \text { ) }\end{array}$ & $\begin{array}{l}\text { Inner layer: laminar interface, } \\
\text { cracks, Mg-F, minor O enrich } \\
\text { Outer layer: Ti-O, minor } \mathrm{Zr} \\
\text { enrich, otherwise dense where } \\
\text { coverage good } \\
\text { Other: Al, C throughout } \\
\text { Corrosion resistance: > bare }\end{array}$ & $\begin{array}{l}\text { Inner layer: laminar interface, } \\
\text { Mg-Ti-F-O, minor Zr, N } \\
\text { enrich } \\
\text { Outer layer: filaments/porous } \\
\text { Zr-Ti-O enrich } \\
\text { Other: C throughout } \\
\text { Corrosion resistance: bare }\end{array}$ \\
\hline $\begin{array}{l}\text { Bonderite } \AA 5200+ \\
\text { electrocoat }\end{array}$ & $\begin{array}{l}\text { Inner layer: laminar interface, } \\
\text { cracks, Mg-Ti-F rich } \\
\text { Outer layer: porous, Mg-O, } \\
\text { minor } \mathrm{Zr} \text { enrich } \\
\text { Other: Al throughout }\end{array}$ & $\begin{array}{l}\text { Inner layer: irregular } \\
\text { interface, thin Mg-Ti-F-O, } \\
\text { Outer layer: intermixed with } \\
\text { electrocoat, diffuse/porous } \\
\text { Mg-Ti-Zr-O enrich } \\
\text { Other: none }\end{array}$ \\
\hline $\begin{array}{l}\text { Surtec }{ }^{\circledR} 650 \text { (primarily adds } \\
\mathrm{O}, \mathrm{Zr}, \mathrm{F}, \mathrm{Cr} \text { ) }\end{array}$ & $\begin{array}{l}\text { Inner layer: laminar interface, } \\
\text { dense, patchy coverage, } \mathrm{Mg}-\mathrm{F}-\mathrm{O} \\
\text { enrich } \\
\text { Outer layer: patchy } \mathrm{Zr}-\mathrm{Cr}-\mathrm{O}\end{array}$ & $\begin{array}{l}\text { Inner layer: laminar interface, } \\
\text { dense, } \mathrm{Mg}-\mathrm{F} \text {, minor O enrich } \\
\text { Outer layer: some voids, } \mathrm{Zr}- \\
\text { Cr-Zn-O enrich }\end{array}$ \\
\hline
\end{tabular}




\begin{tabular}{|l|l|l|}
\hline & $\begin{array}{l}\text { Other: } \mathrm{Al} \text { throughout } \\
\text { Corrosion resistance: }>\text { bare }\end{array}$ & $\begin{array}{l}\text { Other: none } \\
\text { Corrosion resistance: } \sim \text { bare }\end{array}$ \\
\hline Surtec ${ }^{\circ} 650+$ electrocoat & $\begin{array}{l}\text { Single layer only: irregular, } \\
\text { rough interface, cracks, Mg-O } \\
\text { rich, patchy Al, Zn } \\
\text { Other: none }\end{array}$ & $\begin{array}{l}\text { Inner layer: laminar interface, } \\
\text { porous, Mg-F-O rich } \\
\text { Outer layer: diffuse } \mathrm{Zr}- \\
\text { Zn-Al-O enrich } \\
\text { Other: } \text { none }\end{array}$ \\
\hline
\end{tabular}

The as-conversion coated structures for all four alloy/conversion coating combinations could be interpreted as duplex, with an inner, partially oxidized $\mathrm{Mg}-\mathrm{F}$ rich layer and an outer, oxide-rich layer, rich in Ti for BAZ and BE7, and rich in Zr for SAZ and SE7 (see XPS data in Fig. 2). High levels of carbon were also observed throughout the BAZ and BE7 conversion coatings, consistent with its use of an organic polymer in the coating solution. The observed inner Mg-F rich layer is consistent with exposure to fluoride conversion coatings yielding $\mathrm{MgF}_{2}$ and related products, which can enhance corrosion resistance of $\mathrm{Mg}[19,20,25,52]$.

Aluminum was observed to migrate from the Mg-3Al-1Zn AZ31B alloy substrate throughout the conversion coated structures for both BAZ and SAZ (Figs. 2, 8, 10). Neither coating solutions otherwise imparted appreciable $\mathrm{Al}$ to the surface, as evidence by lack of $\mathrm{Al}$ in the conversion coatings formed on E717, which does not contain Al. Compared to the bare alloys, the conversion coatings showed moderate corrosion resistance improvements for AZ31B but not E717 in the saturated $\mathrm{Mg}(\mathrm{OH})_{2}$ with 1 wt.\% $\mathrm{NaCl}$ test solution (Fig. 12), with the strongest effect with BAZ. This observation suggests that the incorporation of Al from the substrate alloy into the conversion coating surface provides a degree of corrosion resistance improvement, whereas Zr from E717 does not. Previous work indicated that Al incorporation into the film formed by uncoated AZ31B in room-temperature distilled water exposures correlated with 
slower film growth by AZ31B than for E717, for which $\mathrm{Zr}$ (primarily as $\mathrm{Zn}_{2} \mathrm{Zr}_{3}$ nanoparticles) was present in the aqueous-formed film [e.g. 49]. The greater gains in as-conversion coated corrosion resistance for $\mathrm{BAZ}$ and $\mathrm{SAZ}$ may result from the thicker film/greater level of $\mathrm{Al}$ enrichment to the film formed with the BAZ (Figs. 2a, c and 3 a,c). However, the further introduction of $\mathrm{C}$ and/or Ti from the $\mathrm{BAZ}$, than for $\mathrm{Zr}$ and $\mathrm{Cr}$ introduced for $\mathrm{SAZ}$, may also play a role.

Zirconium levels were enhanced in the coatings formed on E717 compared to AZ31B (Fig. 2), again indicating migration of $\mathrm{Zr}$ from the substrate alloy during conversion coating (both conversion coatings also impart $\mathrm{Zr}$ to the alloy surface). However, the enhanced $\mathrm{Zr}$ levels in the coating, particularly for SE7, did not significantly impact the potentiodynamic polarization behavior of the as-conversion coated surface vs. bare alloy in the saturated $\operatorname{Mg}(\mathrm{OH})_{2}$ with 1 wt.\% $\mathrm{NaCl}$ test solution (Fig. 12 b,d).

Subsequent electrocoating of the as-conversion coated surfaces significantly modified chemistry and morphology at the metal-coating interface for all four alloy/conversion coating combinations (Figs 4-11). Although the same, standard electrocoating processing were used on all samples, the impact on the metal-coating interface structure varied with the conversion coating/alloy substrate combination. For all samples, electrocoating resulted in increased porosity and modified chemistry by dispersal of $\mathrm{F}, \mathrm{Ti}, \mathrm{Zr}, \mathrm{Cr}$ additives at the metal-coating interface initially formed during conversion coating. This indicates a degree of corrosive attack of the conversion coated substrate alloy resulting from the electrocoating. It could result from the strong cathodic hydrogen evolution and oxygen reduction occurring at the substrate/conversion coating interface 
during the electrocoating process. Moreover, the migration of $\mathrm{OH}$ - from the substrate to the bulk solution may also bring some elements and compounds that are reactive with hydroxyl from the inner layer of the conversion coating outward.

Cross-section SEM and STEM analysis suggested that the conversion coated-metal interface was best retained after electrocoating for BAZ + electrocoat (Figs. 4 and 8) and SE7 + electrocoat (Figs. 7 and 11). For the BE7 + electrocoat (Figs. 5, 9) and SAZ+ electrocoat (Figs. 6, 10), extensive disruption and oxidation at the metal-coating interface after electrocoating were observed. However, corrosion testing in saturated $\mathrm{Mg}(\mathrm{OH})_{2}$ with 1 wt. $\% \mathrm{NaCl}$ test solution still indicated extensive corrosion and variability in electrocoating protectiveness for duplicate samples among all alloy/coating combinations studied (Fig. 13). Such variability is in part reflective of the aggressive nature of the $48 \mathrm{~h}$ immersion in salt solution used to evaluate the electrocoatings, as well as the evaluation of conversion coated + electrocoated Mg alloys without additional top coat layers such as enamels, sealants, or paints [e.g. 23].

However, the variability in electrocoating protectiveness in the present work is also considered indicative of excessively variable levels of coating defects sample to sample after the electrocoating employed. The prevalence of coating defects are hypothesized to be impacted, at least in part, by the degree to which the initial conversion coating was disrupted by the electrocoating, leading to poor local adherence and/or more vulnerable chemistries. This finding underlines the challenge of coating $\mathrm{Mg}$ alloys, and the need to finely tune electrocoating processing in light of potential degradation of the initial conversion coating during electrocoating. 


\subsection{Conclusions}

The local metal-coating interface microstructure and chemistry formed on AZ31B and E717 (ZE10A) were analyzed by SEM, XPS, and STEM as-conversion coated with a commercial hexafluoro-titanate/zirconate type + organic polymer based treatment (Bonderite ${ }^{\circledR} 5200$ ), BAZ and BE7 on AZ31B and E717, respectively, and a commercial hexofluoro-zirconate type + trivalent chromium $\mathrm{Cr}^{+3}$ type treatment (Surtec ${ }^{\circledR}$ 650), SAZ and SE7, and after the same conversion coatings followed by electrocoating with epoxy-based Cathoguard® 525 . Corrosion behavior of bare and coated samples was assessed in aqueous saturated $\mathrm{Mg}(\mathrm{OH})_{2}$ with 1 wt.\% $\mathrm{NaCl}$, and the observed trends correlated with the coating chemistries and structure.

1) The conversion coatings were submicron and duplex, with inner, partially oxidized Mg-F rich layers and an outer layer containing oxides of additives of the conversion coating, $\mathrm{Ti}$, and $\mathrm{Zr}$ for BAZ and BE7, and $\mathrm{Zr}$ and $\mathrm{Cr}$ for SAZ and SE7. The conversion coatings produced were moderately thicker for BAZ and BE7 than for SAZ and SE7, with C also introduced throughout the BAZ and BE7 films (the BE7 film, however, was also more porous).

2) The substrate alloy played a role in the resulting conversion coating chemistry, with Al from the AZ31B substrate alloy and Zr from the E717 substrate alloy migrating into the conversion coatings. The incorporation of Al into the conversion coatings formed on AZ31B moderately enhanced corrosion resistance, particularly for BAZ. In contrast, the incorporation of $\mathrm{Zr}$ into the conversion coatings formed on E717 had little impact on corrosion resistance. 
3) Electrocoating increased porosity and modified the chemistry of the metal-coating interface structures initially formed during conversion coating, resulting in dispersal of $\mathrm{F}$, $\mathrm{Ti}, \mathrm{Zr}$, and $\mathrm{Cr}$ conversion-coating additives. These changes indicate a degree of corrosive attack and degradation of the conversion-coated surface by the electrocoat process employed, and were postulated to contribute to local defects which can compromise the protectiveness of the electrocoating. Although the same nominal electrocoating processing was used on all samples studied, the degree of impact on the metal-coating interface structure varied with the conversion coating/alloy substrate combination. These observations highlight the challenges of coating $\mathrm{Mg}$, and the need to tailor electrocoating in light of potential degradation of the initial as-conversion coated Mg alloy surface.

\subsection{Acknowledgements}

The authors thank D.W. Coffey, T.M. Lowe, T. Geer and T.L. Jordan for assistance with the experimental work. M. Lance, B. Armstrong, and B.A. Pint provided helpful comments for this manuscript. This research was sponsored by the U.S. DOE EERE Vehicle Technologies Office. TEM/STEM characterization work made use of capabilities at the ORNL Center for Nanophase Materials Sciences, which is a DOE Office of Science User Facility.

\subsection{References}

1. A.A. Luo, Magnesium: Current and potential automotive applications, Jom-Journal of the Minerals Metals \& Materials Society, 54 (2002) 42-48.

2. C. Blawert, N. Hort, K.U. Kainer, Automotive applications of magnesium and its alloys, Transactions of the Indian Institute of Metals, 57 (2004) 397-408.

3 I. Johnson, H.N. Liu, A Study on Factors Affecting the Degradation of Magnesium and a Magnesium-Yttrium Alloy for Biomedical Applications, Plos One, 8 (2013).

4. A. Atrens, G.L. Song, M. Liu, Z.M. Shi, F.Y. Cao, M.S. Dargusch, Review of Recent 
Developments in the Field of Magnesium Corrosion, Adv. Eng. Mater., 17 (2015) 400-453.

5. K. Gusieva, C.H.J. Davies, J.R. Scully, N. Birbilis, Corrosion of magnesium alloys: the role of alloying, Int. Mater. Rev., 60 (2015) 169-194.

6. S. Thomas, N.V. Medhekar, G.S. Frankel, N. Birbilis, Corrosion mechanism and hydrogen evolution on Mg, Current Opinion in Solid State \& Materials Science, 19 (2015) 85-94.

7. E. Ghali, W. Dietzel, K.U. Kainer, General and localized corrosion of magnesium alloys: A critical review, J. Mater. Eng. Perform., 13 (2004) 7-23.

8. N. Hara, Y. Kobayashi, D. Kagaya, N. Akao, Formation and breakdown of surface films on magnesium and its alloys in aqueous solutions, Corros. Sci., 49 (2007) 166-175.

9. G.L. Makar, J. Kruger, Corrosion Of Magnesium, Int. Mater. Rev., 38 (1993) 138-153. 10. makar 1993 CORROSION OF MAGNESIUMInternational Materials Reviews

11. G.L. Song, A. Atrens, Corrosion mechanisms of magnesium alloys, Adv. Eng. Mater., 1 (1999) 11-33.

12. F.Y. Cao, Z.M. Shi, J. Hofstetter, P.J. Uggowitzer, G.L. Song, M. Liu, A. Atrens, Corrosion of ultra-high-purity $\mathrm{Mg}$ in 3.5\% $\mathrm{NaCl}$ solution saturated with $\mathrm{Mg}(\mathrm{OH})(2)$, Corros. Sci., 75 (2013) 78-99.

13. M.C. Zhao, P. Schmutz, S. Brunner, M. Liu, G.L. Song, A. Atrens, An exploratory study of the corrosion of Mg alloys during interrupted salt spray testing, Corros. Sci., 51 (2009) 12771292.

14. R.C. Zeng, J. Zhang, W.J. Huang, W. Dietzel, K.U. Kainer, C. Blawert, W. Ke, Review of studies on corrosion of magnesium alloys, Transactions of Nonferrous Metals Society of China, 16 (2006) S763-S771.

15. J.R. Kish, Y. Hu, J. Li, W. Zheng, J.R. McDermid, Technical Note: Examination of Focused Ion Beam-Sectioned Surface Films Formed on AM60B Mg Alloy in an Aqueous Saline Solution, Corrosion, 68 (2012) 468-474.

16. M.P. Brady, G. Rother, L.M. Anovitz, K.C. Littrell, K.A. Unocic, H.H. Elsentriecy, G.L. Song, J.K. Thomson, N.C. Gallego, B. Davis, Film Breakdown and Nano-Porous $\mathrm{Mg}(\mathrm{OH})(2)$ Formation from Corrosion of Magnesium Alloys in Salt Solutions, J. Electrochem. Soc., 162 (2015) C140-C149.

17. J.E. Gray, B. Luan, Protective coatings on magnesium and its alloys - a critical review, J. Alloys Compd., 336 (2002) 88-113.

18. X.B. Chen, H.Y. Yang, T.B. Abbott, M.A. Easton, N. Birbilis, Magnesium: Engineering the Surface, JOM, 64 (2012) 650-656. 
19. X.B. Chen, N. Birbilis, T.B. Abbott, Review of Corrosion-Resistant Conversion Coatings for Magnesium and Its Alloys, Corrosion, 67 (2011).

20. S. Verdier, N. van der Laak, F. Dalard, J. Metson, S. Delalande, An electrochemical and SEM study of the mechanism of formation, morphology, and composition of titanium or zirconium fluoride-based coatings, Surface \& Coatings Technology, 200 (2006) 2955-2964.

21 S. Song, W.D. Shen, M.H. Liu, G.L. Song, Corrosion study of new surface treatment/coating for AZ31B magnesium alloy, Surf. Eng., 28 (2012) 486-490.

22 R. C. McCune, V. Upadhyay, Y-M Wang, D. Battocchi, The Use Of AC-DC-AC Methods in Assessing Corrosion Resistance Performance of Coating Systems For Magnesium Alloys, in: N. Hart, S.N. Mathaudhu, N.R. Neelameggham, M. Aldennan, (Eds.) Magnesium Technology 2013, TMS (The Minerals, Metals \& Materials Society), Warrendale, PA 15086-7514 USA, 2013 pp. 163-168.

23. J. R. Kish, Z. Cano, A. Kobylecky, J.R. McDermid, T. Skszek, Comparative Corrosion Assessment of Coated Alloys for Multi-Material Lightweight Vehicle Architectures, Society of Automotive Engineers International, Warrendale, PA, USA, SAE Technical Paper 2015-010738, 2015, oi:10.4271/2015-01-0738.

24. S. Stojadinovic, R. Vasilic, J. Radic-Peric, M. Peric, Characterization of plasma electrolytic oxidation of magnesium alloy AZ31 in alkaline solution containing fluoride, Surface \& Coatings Technology, 273 (2015) 1-11.

25. S. Verdier, N. van der Laak, S. Delalande, J. Metson, F. Dalard, The surface reactivity of a magnesium-aluminium alloy in acidic fluoride solutions studied by electrochemical techniques and XPS, Appl. Surf. Sci., 235 (2004) 513-524.

26. ZP Cano, JR Kish, JR McDermid, Global and Localized Corrosion Behaviour of a Coated AM60B Magnesium Alloy, Materials Science and Technology (MS\&T) 2013 Conference Proceedings, Warrendale, PA 15086-7514 USA, 2013, pp. 1591-1599

27. Y. Gao, A. Yerokhina, A. Matthews, Deposition and evaluation of duplex hydroxyapatite and plasma electrolytic oxidation coatings on magnesium, Surface and Coatings Technology, 269 (2015), 170-182

28. G. Gao and M. Ricketts, Evaluation of Protective Coatings on Magnesium for Phosphate Process Compatibility and Galvanic Corrosion Prevention, Society of Automotive Engineers International, Warrendale, PA, USA, SAE Technical Paper 2002-01-0081, 2002, DOI:10.4271/2002-01-0081 
29. G. Wang, K. Stewart, R. Berkmortel, J.Skar, Corrosion Prevention for External Magnesium Automotive Components," Society of Automotive Engineers International, Warrendale, PA, USA, SAE Technical Paper 2001-01-0421, 2001, doi:10.4271/2001-01-0421.

30. W.Y. Zheng, C. Derushie, J. Lo, Protection of Mg alloys against galvanic and other forms of corrosion, Magnesium - Science, Technology and Applications, 488-489 (2005) 787-791.

31. H.H. Elsentriecy, K. Azumi, H. Konno, Effect of surface pretreatment by acid pickling on the density of stannate conversion coatings formed on AZ91 D magnesium alloy, Surface \& Coatings Technology, 202 (2007) 532-537.

32. H.H. Elsentriecy, J. Qu, H.M. Luo, H.M. Meyer, C. Ma, M.F. Chi, Improving corrosion resistance of AZ31B magnesium alloy via a conversion coating produced by a protic ammonium-phosphate ionic liquid, Thin Solid Films, 568 (2014) 44-51.

33. R. Hu, S. Zhang, J. Bu, C. Lin, G.-L. Song, Recent progress in corrosion protection of magnesium alloys by organic coatings, Progress in Organic Coatings, 73(2012)129-141

34. Z. Wang, F.Jia, L. Yu, Z. Qi, Y. Tang, G.-L. Song, Direct Electroless Nickel-Boron Plating on AZ91D Magnesium Alloy, Surface \& Coatings technology, 206 (17) (2012)3676-3685

35. Y. Chen, B. Luan, G.-L. Song, Q. Yang, D. Kingston, F. Bensebaa, An investigation of new barium phosphate chemical conversion coating on AZ31 magnesium alloy, Surface \& Coatings Technology, 210(2012)156-165

36. G.-L. Song, A dipping Electrocoating for Mg alloys, Progress in Organic coatings, 70:252$258(2011)$

37. G. Song, An irreversible dipping sealing technique for anodized ZE41 Mg alloy, Surface \& Coatings Technology, 203 (2009)3618-3625

38. G. Song, "Electroless" Electrocoating ---An Innovative Surface Treatment for Magnesium Alloys, Electrochemical and Solid-State Letters, 12(10) D77-D79 (2009)].

39. G.-L. Song, Z.Shi, Corrosion mechanism and evaluation of anodized magnesium alloys, Corrosion Science 85 (2014) 126-140

40. G.-L. Song, M. Liu, The Effect of Mg Alloy Substrate on "Electroless" Electrocoating Performance, Corrosion Science, 53 (2011) 3500-3508].

41. W. Zheng, C. Derushie, R. Zhang, J. Lo, Protection of Mg Alloys for Structural Applications in Automobiles," Society of Automotive Engineers International, Warrendale, PA, USA, SAE Technical Paper 2004-01-0133, 2004, doi:10.4271/2004-01-0133.

42. Y. C. Yang, C. Y. Tsai, Y. H. Huang, and C. S. Linz, Formation Mechanism and Properties of Titanate Conversion Coating on AZ31 Magnesium Alloy, Journal of The Electrochemical Society, 159 (5), 2012, C226-C232. 
43. C. S. Linz and S. K. Fang, Formation of Cerium Conversion Coatings on AZ31

Magnesium Alloys, Journal of The Electrochemical Society, 152 (2), 2005, B54-B59

44. J.H. Nordlien, J.C. Walmsley, H. Osterberg, K. Nisancioglu, Formation of a zirconiumtitanium based conversion layer on AA 6060 aluminium, Surface \& Coatings Technology, 153 (2002) $72-78$.

45. L.L. Li, B.W. Whitman, G.M. Swain, Characterization and Performance of a $\mathrm{Zr} / \mathrm{Ti}$

Pretreatment Conversion Coating on AA2024-T3, J. Electrochem. Soc., 162 (2015) C279-C284.

46. J.-T. Qi, T. Hashimoto, J.R.Walton, X. Zhou, P. Skeldon, G.E. Thompson, Trivalent chromium conversion coating formation on aluminum, Surface \& Coatings Technology 280 (2015) 317-329

47. R. M. Asmussen, W. J. Binns, P. Jakupi, and D. Shoesmith, The Influence of Microstructure on the Corrosion of Magnesium Alloy ZEK100, Corrosion, 71(2) (2015) 242-254.

48. Z.P. Cano, M. Danaie, J.R. Kish, J.R. McDermid, G.A. Botton, and G. Williams, Physical Characterization of Cathodically-Activated Corrosion Filaments on Magnesium Alloy AZ31B, Corrosion, Corrosion, 71 (2) (2015), 146-159.

49. K.A. Unocic, H.H. Elsentriecy, M.P. Brady, H.M. Meyer, G.L. Song, M. Fayek, R.A. Meisner, B. Davis, Transmission Electron Microscopy Study of Aqueous Film Formation and Evolution on Magnesium Alloys, J. Electrochem. Soc., 161 (2014) C302-C311.

50. X.P. Niu, T. Skszek, M. Fabischek, A. Zak, Low Temperature Warm Forming of Magnesium ZEK 100 Sheets for Automotive Applications, Mater. Sci. For., (2014), 431, 783-786.

51. L.L. Li, A.L. Desouza, G.M. Swain, In situ pH measurement during the formation of conversion coatings on an aluminum alloy (AA2024), Analyst, 138 (2013) 4398-4402.

52. E. Gulbrandsen, J. Tafto, A. Olsen, The Passive Behavior Of Mg In Alkaline Fluoride Solutions - Electrochemical And Electron-Microscopic Investigations, Corros. Sci., 34 (1993) 1423-1440.

\section{Figure Captions}

Fig. 1- Backscatter mode SEM images of the as-conversion coated surfaces formed on AZ31B and E717.

Fig. 2- XPS elemental profiles of the as-conversion coated surfaces formed on AZ31B and E717. 
Fig. 3- Backscatter mode SEM cross-section images of the as-conversion coated surfaces formed on AZ31B and E717.

Fig. 4 - Backscatter mode SEM cross-section images and elemental maps of BAZ + electrocoat.

Fig. 5 - Backscatter mode SEM cross-section images and elemental maps of the BE7 + electrocoat.

Fig. 6 - Backscatter mode SEM cross-section images and elemental maps of SAZ + Electrocoat.

Fig. 7 - Backscatter mode SEM cross-section images and elemental maps of SE7 + electrocoat.

Fig. 8 - Cross-Section dark field STEM images and corresponding elemental maps for asconversion coated BAZ (a) and the coating-substrate interfacial region after subsequent application of the BAZ + electrocoat. (b)

Fig. 9 - Cross-Section dark field STEM images and corresponding elemental maps for asconversion coated BE7 (a) and the coating-substrate interfacial region after subsequent application of the BE7 + electrocoat. (b)

Fig. 10 - Cross-Section dark field STEM images and corresponding elemental maps for asconversion coated SAZ (a) and the coating-substrate interfacial region after subsequent application of SAZ + electrocoat. (b)

Fig. 11 - Cross-Section dark field STEM images and corresponding elemental maps for asconversion coated SE7 (a) and the coating-substrate interfacial region after subsequent application of the SE7 + electrocoat. (b)

Fig. 12 - Potentiodynamic polarization data for AZ31B and E717 bare and as-conversion coated in saturated $\mathrm{Mg}(\mathrm{OH})_{2}+1 \mathrm{wt} \% \mathrm{NaCl}$ at room temperature.

Fig. 13- Photographs of conversion coated + electrocoated AZ31B and E717 test samples after corrosion screening of $48 \mathrm{~h}$ immersion in $\mathrm{Mg}(\mathrm{OH})_{2}+1 \mathrm{wt} . \% \mathrm{NaCl}$ at room temperature followed by potentiodynamic polarization from $\sim-1.75 \mathrm{~V}$ to $\sim-0.9 \mathrm{~V}$ vs $\mathrm{Ag} / \mathrm{AgCl}$ (start/finish voltage ranges varied sample run to sample run by $\sim \pm 0.1 \mathrm{~V}$ except for SAZ + electrocoat run 2 , which started at $-1.45 \mathrm{~V})$. Test samples were $15 \mathrm{~mm}$ diameter, with exposed area of $10 \mathrm{~mm}$ diameter marked by red dashed line (the as-electrocoated surface was black). 
a) $B A Z$

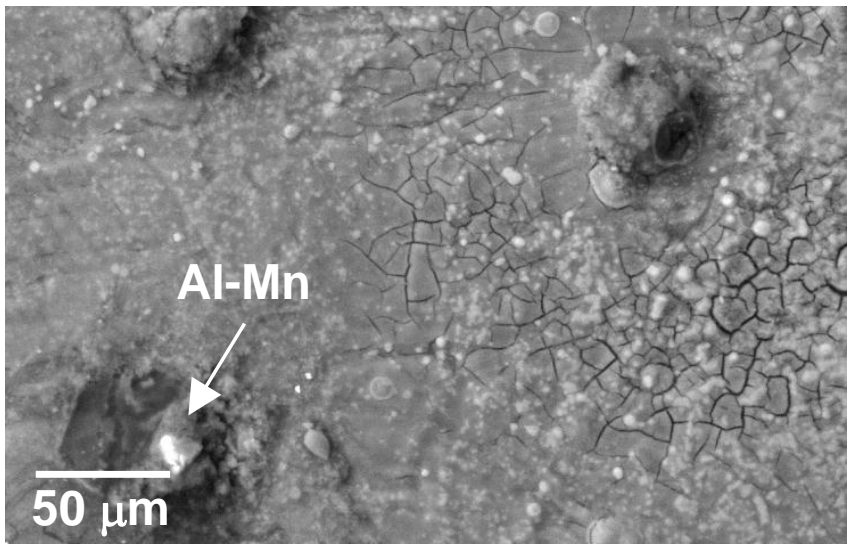

c) SAZ

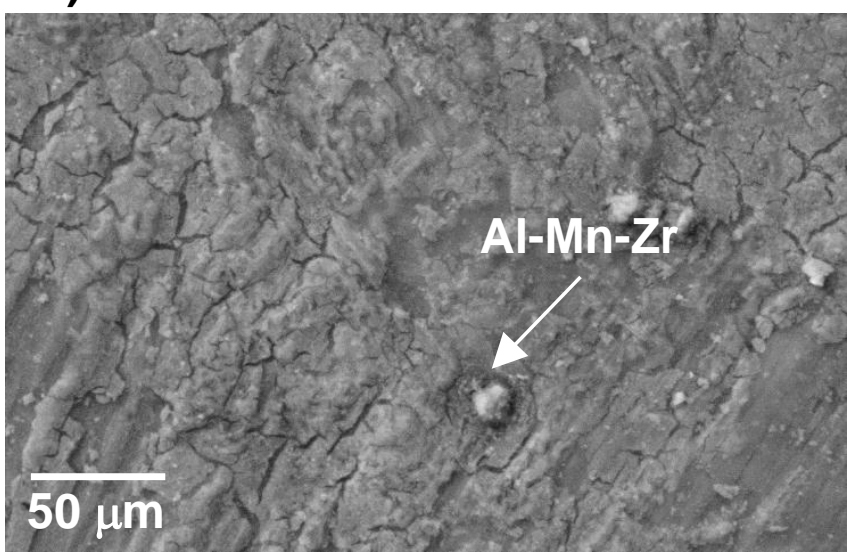

b) BE7

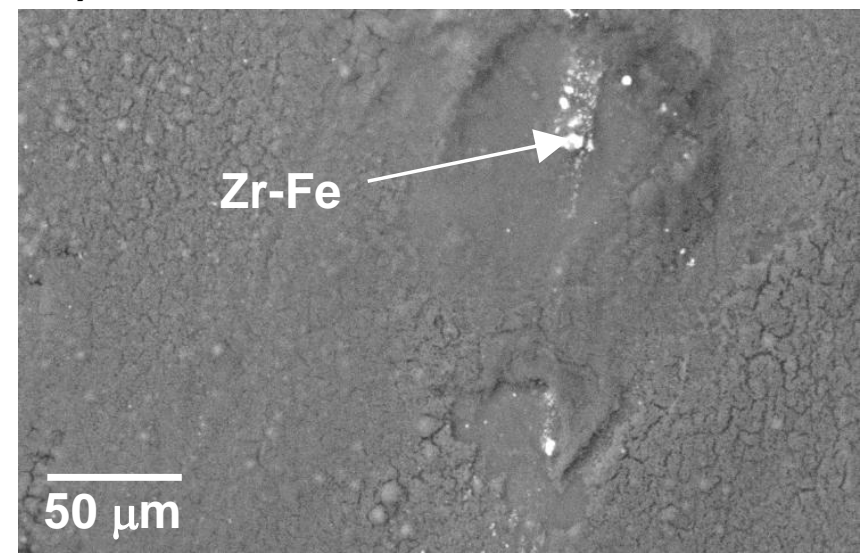

d) SE7

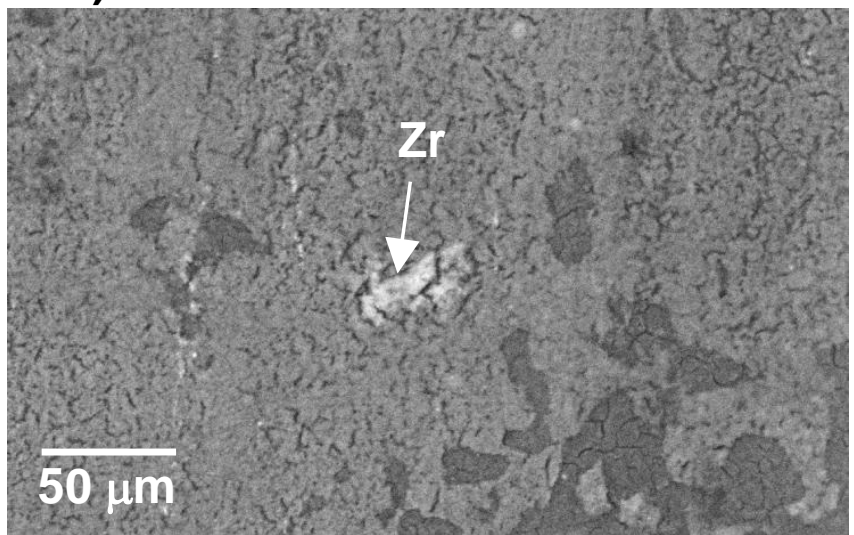

Fig. 1- Backscatter mode SEM images of the as-conversion coated surfaces formed on AZ31B and E717. 
a) BAZ

b) BE7
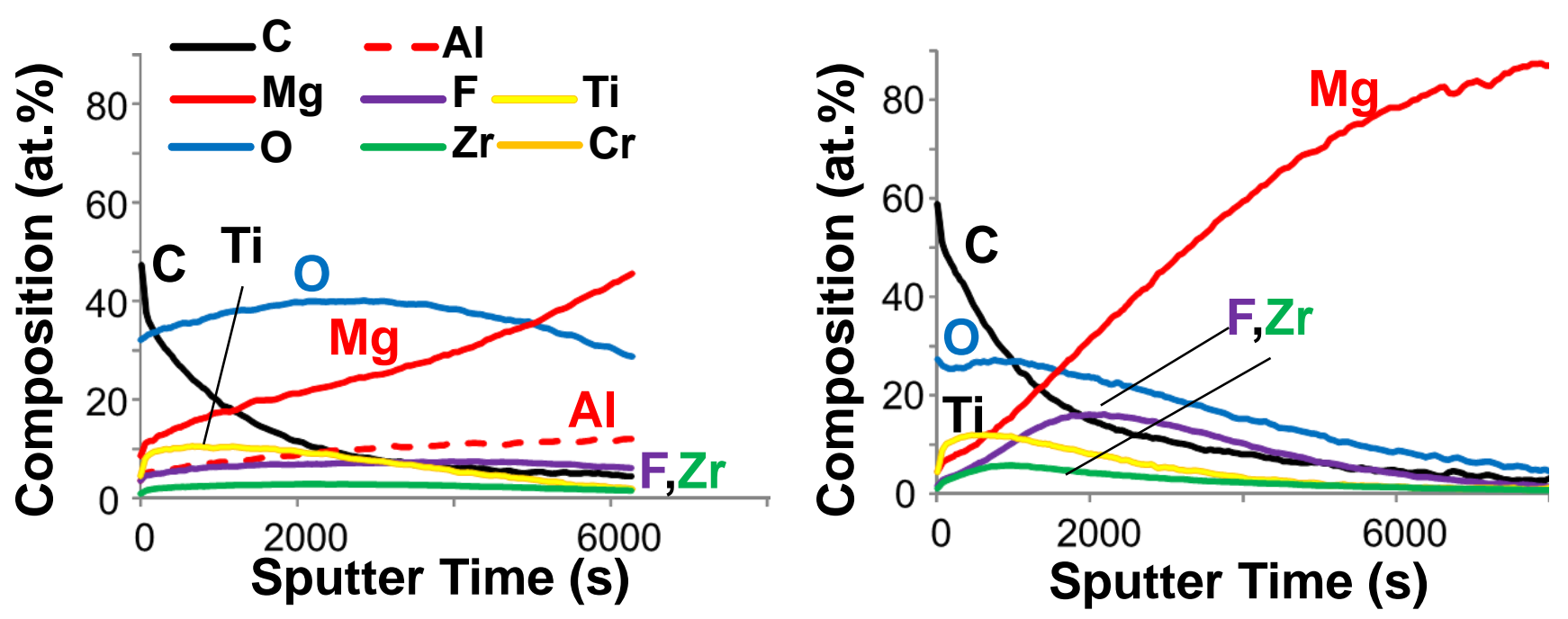

c) SAZ

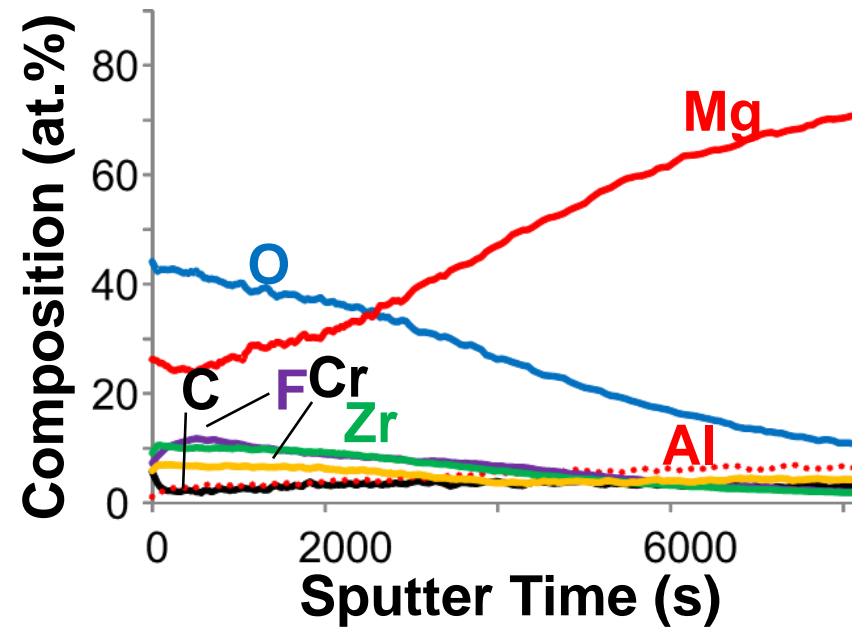

d) SE7

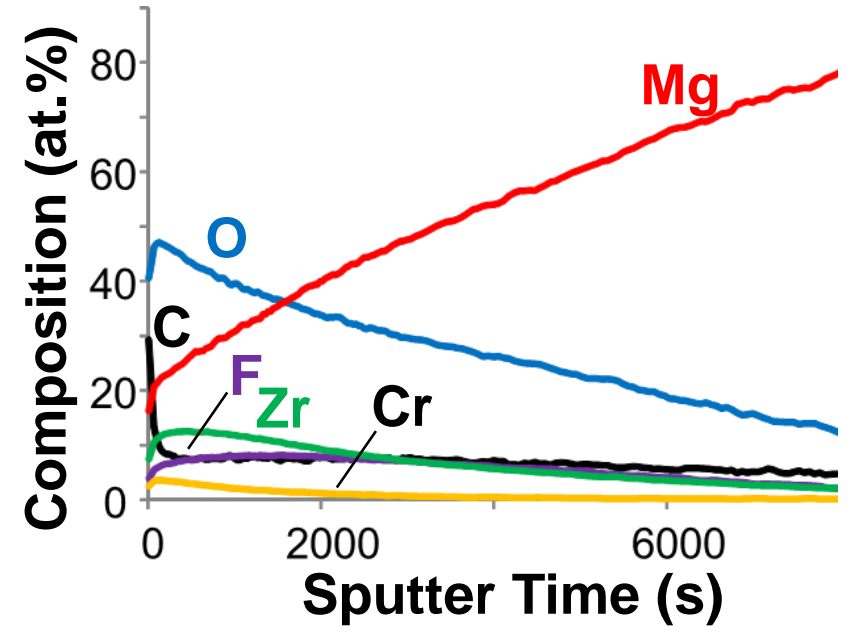

Surface Composition (at.\%) Prior to Sputtering

\begin{tabular}{llllllllllll} 
& $\mathrm{Mg}$ & $\mathrm{O}$ & $\mathrm{Al}$ & $\mathrm{C}$ & $\mathrm{Zr}$ & $\mathrm{Cr}$ & $\mathrm{Ti}$ & $\mathrm{F}$ & $\mathrm{S}$ & $\mathrm{N}$ & $\mathrm{Zn}$ \\
\hline BAZ & 9.9 & 30.5 & 1.8 & 49.7 & 0.4 & 0.3 & 2.8 & 2.5 & 0.0 & 2.0 & 0.2 \\
BE7 & 2.5 & 24.5 & 0.0 & 65.8 & 0.6 & 0.3 & 2.4 & 1.3 & 0.0 & 2.5 & 0.1 \\
SAZ & 8.5 & 48.9 & 1.1 & 22.1 & 6.4 & 5.2 & 0.0 & 7.0 & 0.8 & 0.0 & 0.0 \\
SE7 & 9.4 & 43.2 & 0.2 & 34.0 & 6.0 & 3.0 & 0.0 & 3.4 & 0.3 & 0.4 & 0.1
\end{tabular}

Fig. 2- XPS elemental profiles of the as-conversion coated surfaces formed on AZ31B and E717. 
a) BAZ

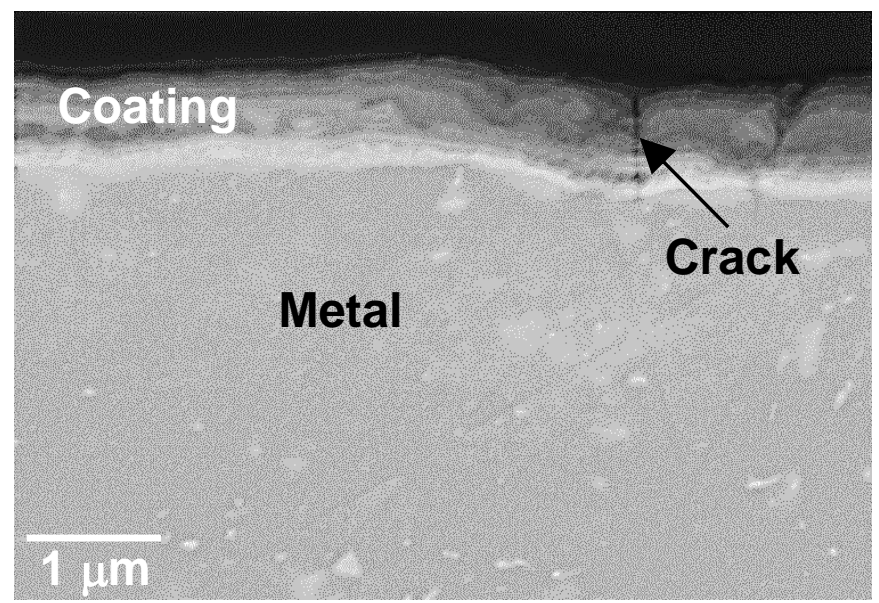

c) SAZ

\section{Coating}

Metal

Coverage Gap

$1 \mu \mathrm{m}$ b) BE7

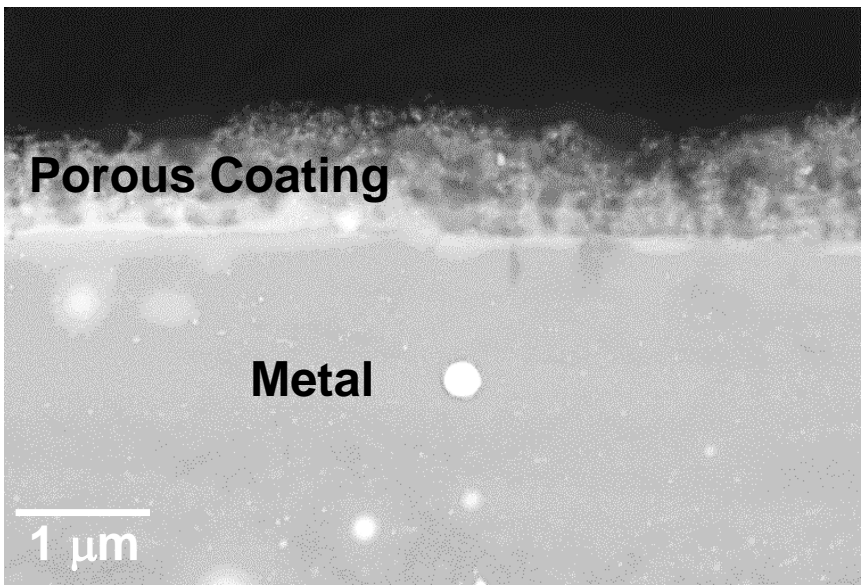

d) SE7

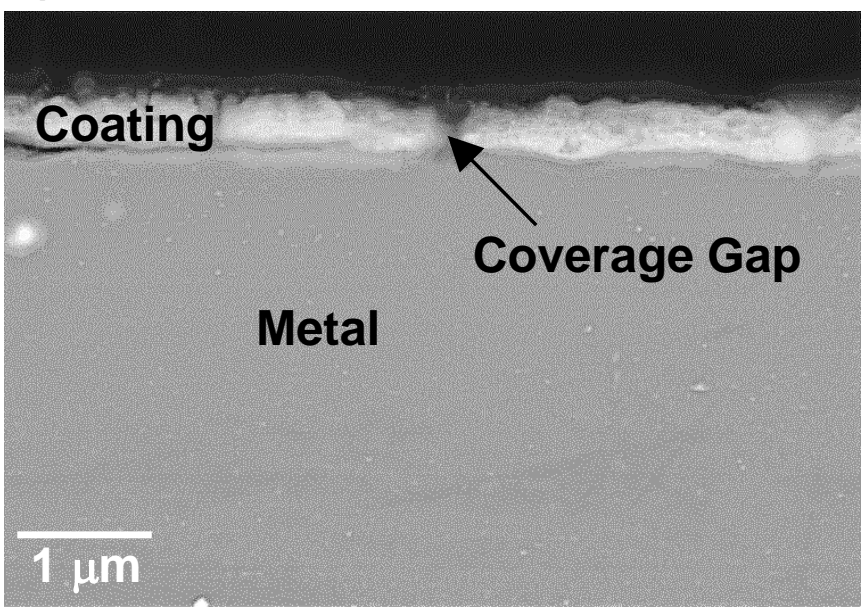

Fig. 3- Backscatter mode SEM cross-section images of the as-conversion coated surfaces formed on AZ31B and E717. 

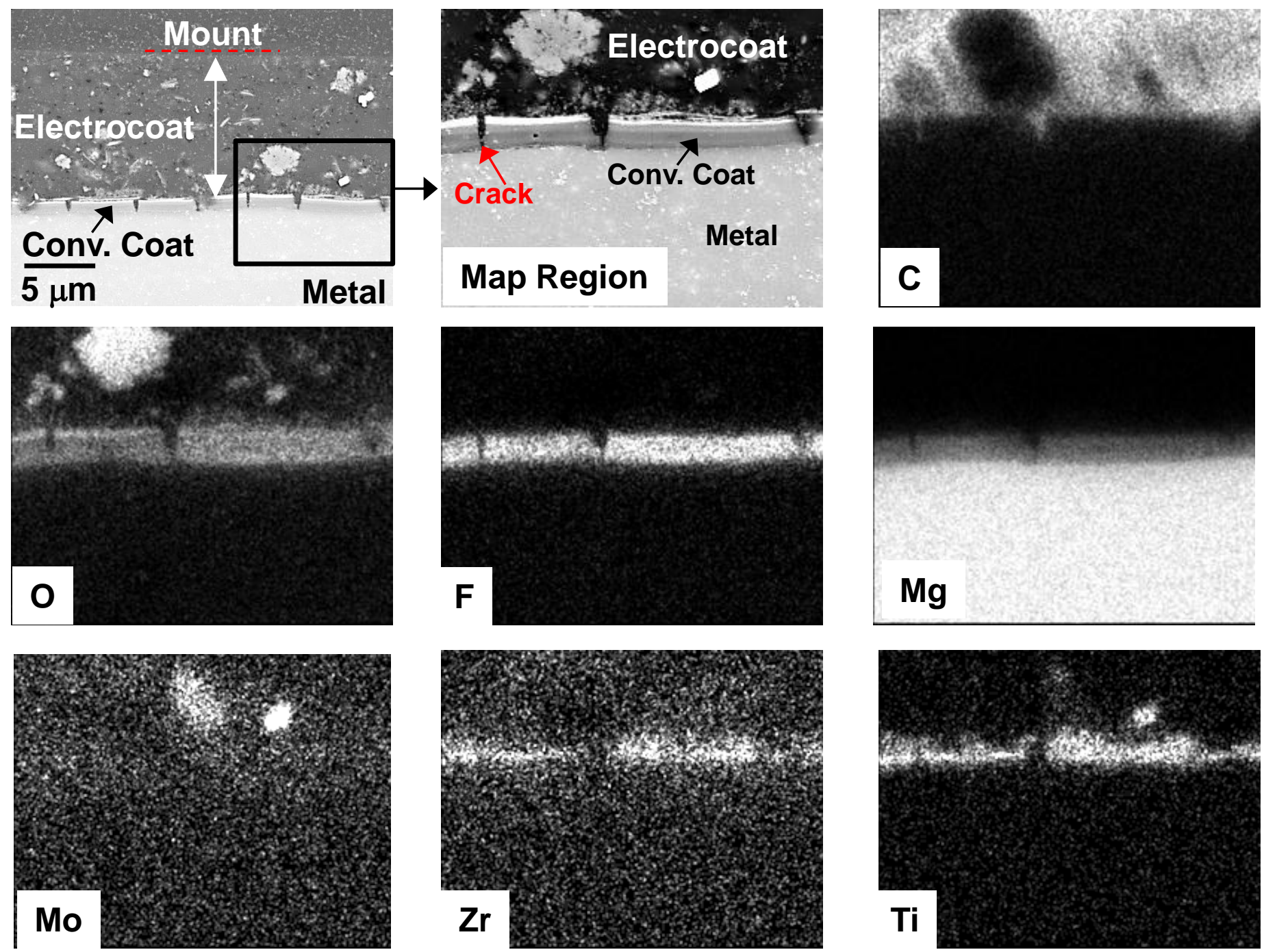

\section{Mg}
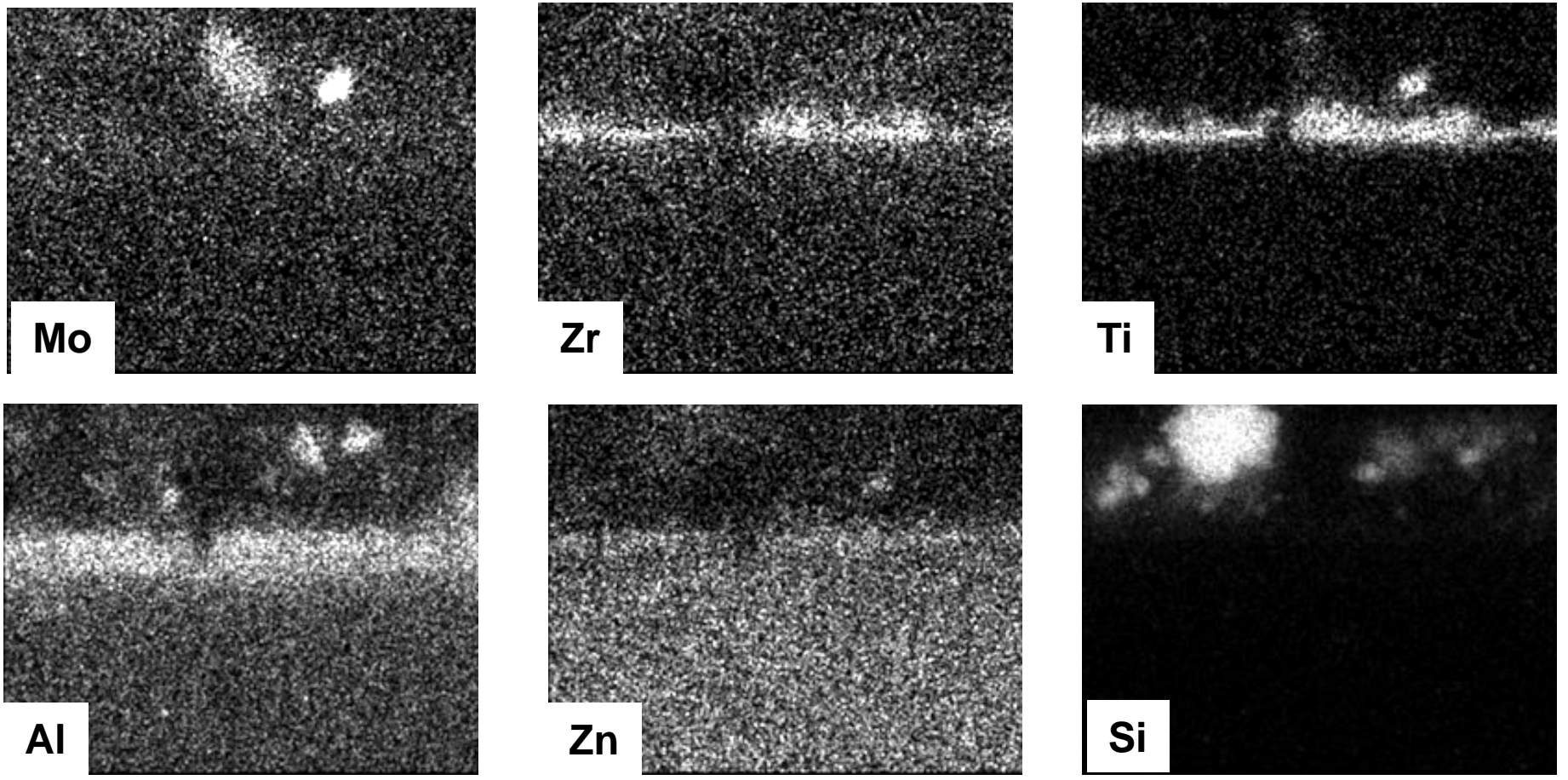

Fig. 4 - Backscatter mode SEM cross-section images and elemental maps of BAZ + electrocoat. 

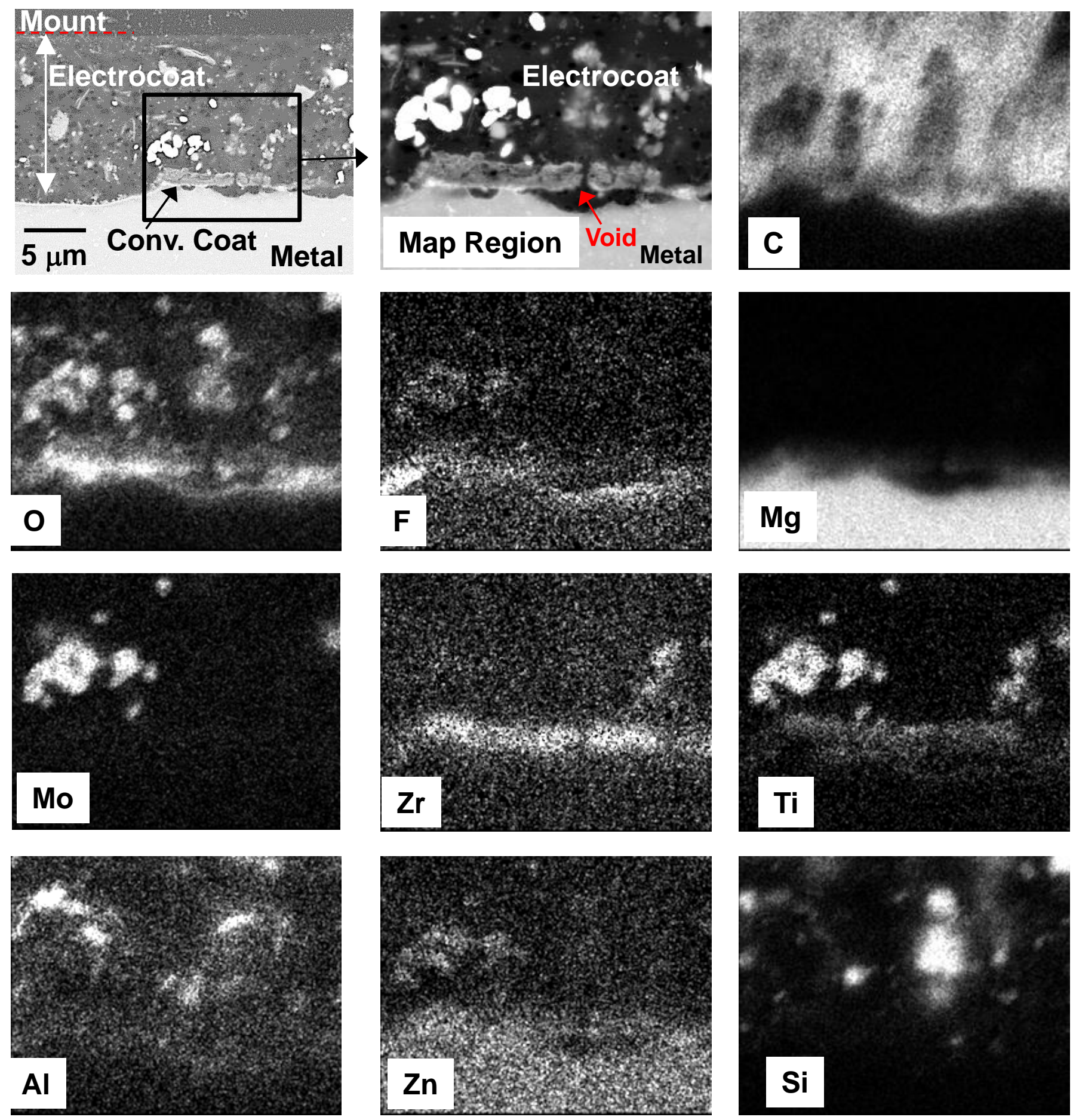

Fig. 5 - Backscatter mode SEM cross-section images and elemental maps of the BE7 electrocoat. 

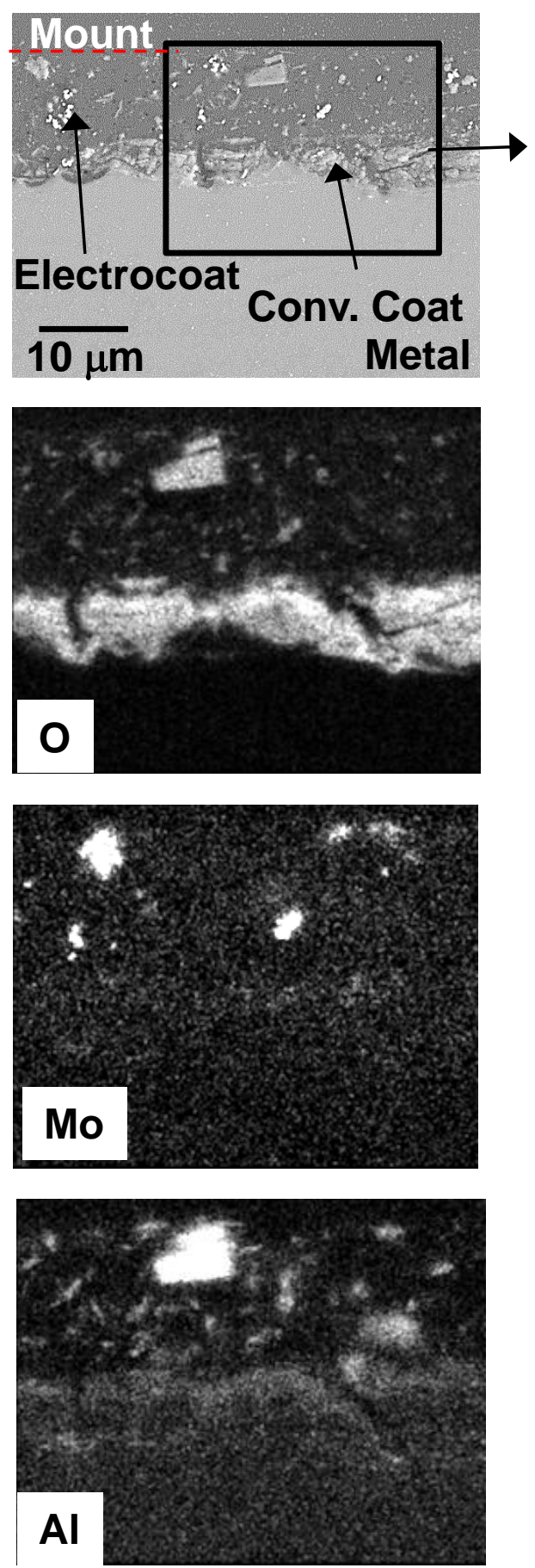
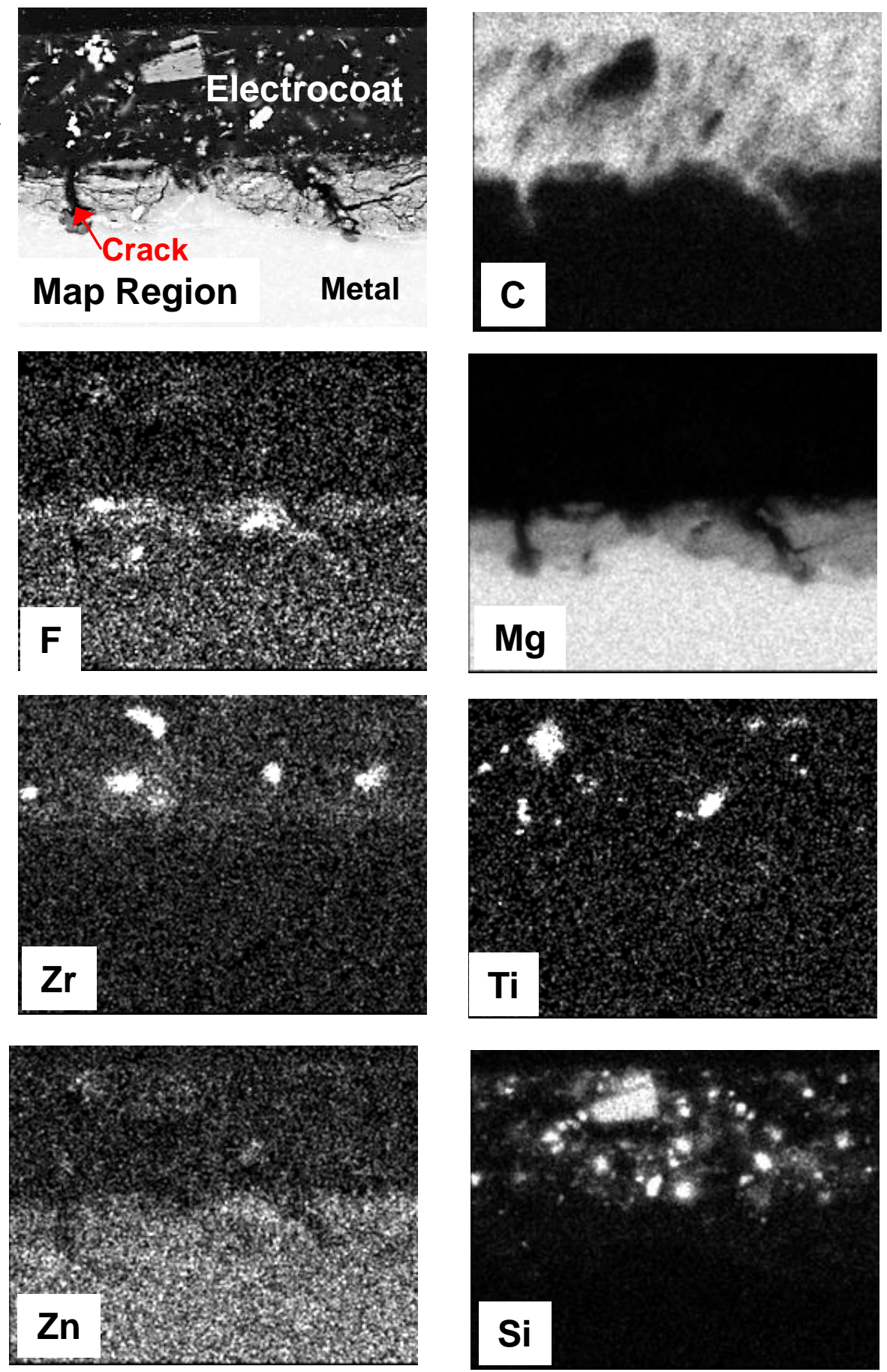

$\mathrm{Mg}$
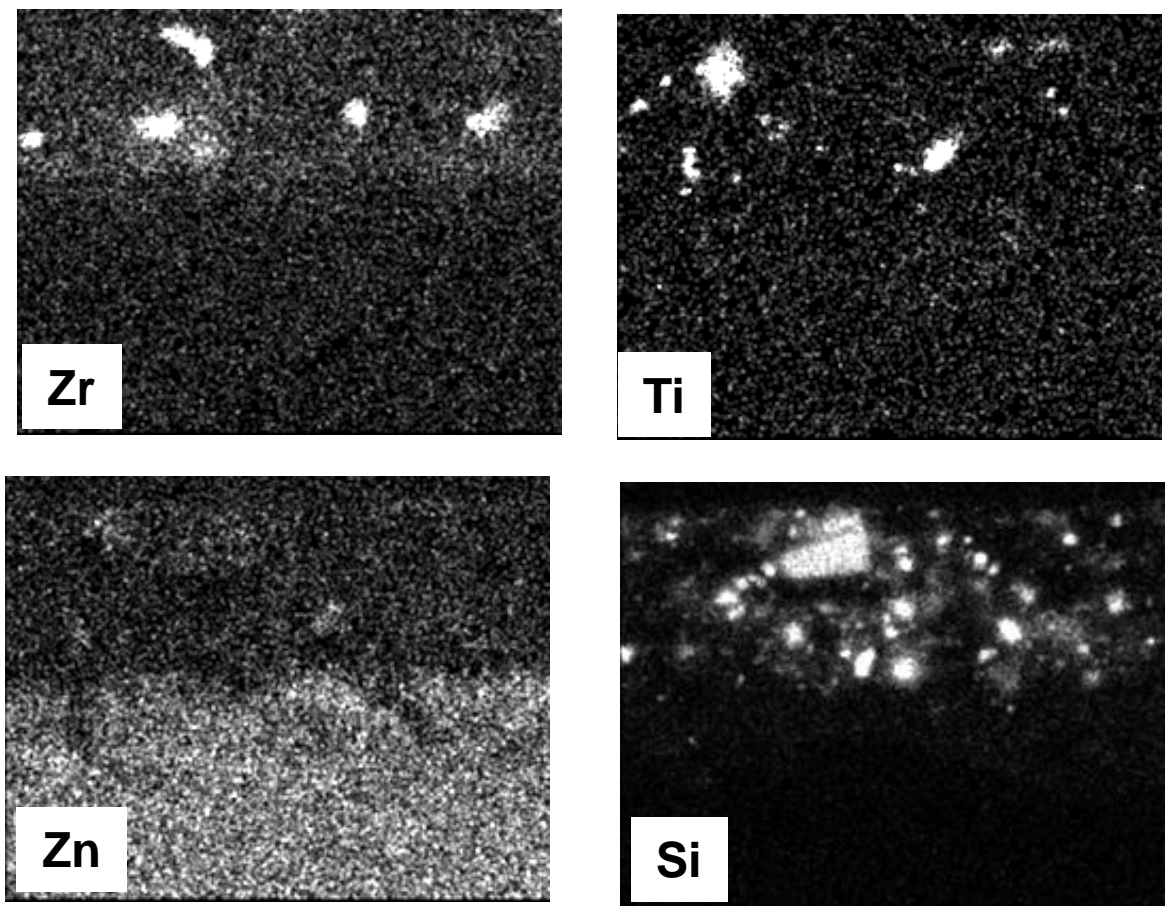

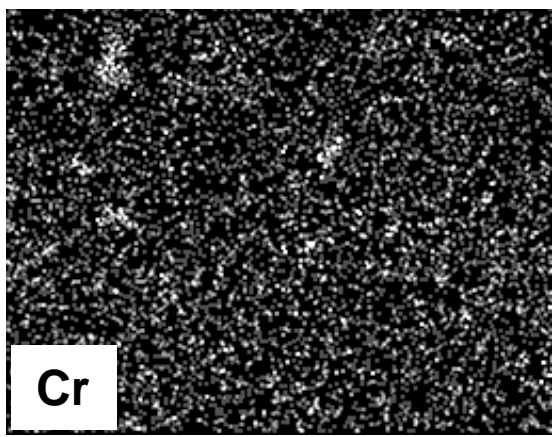

Fig. 6 - Backscatter mode SEM cross-section images and elemental maps of SAZ + electrocoat. 

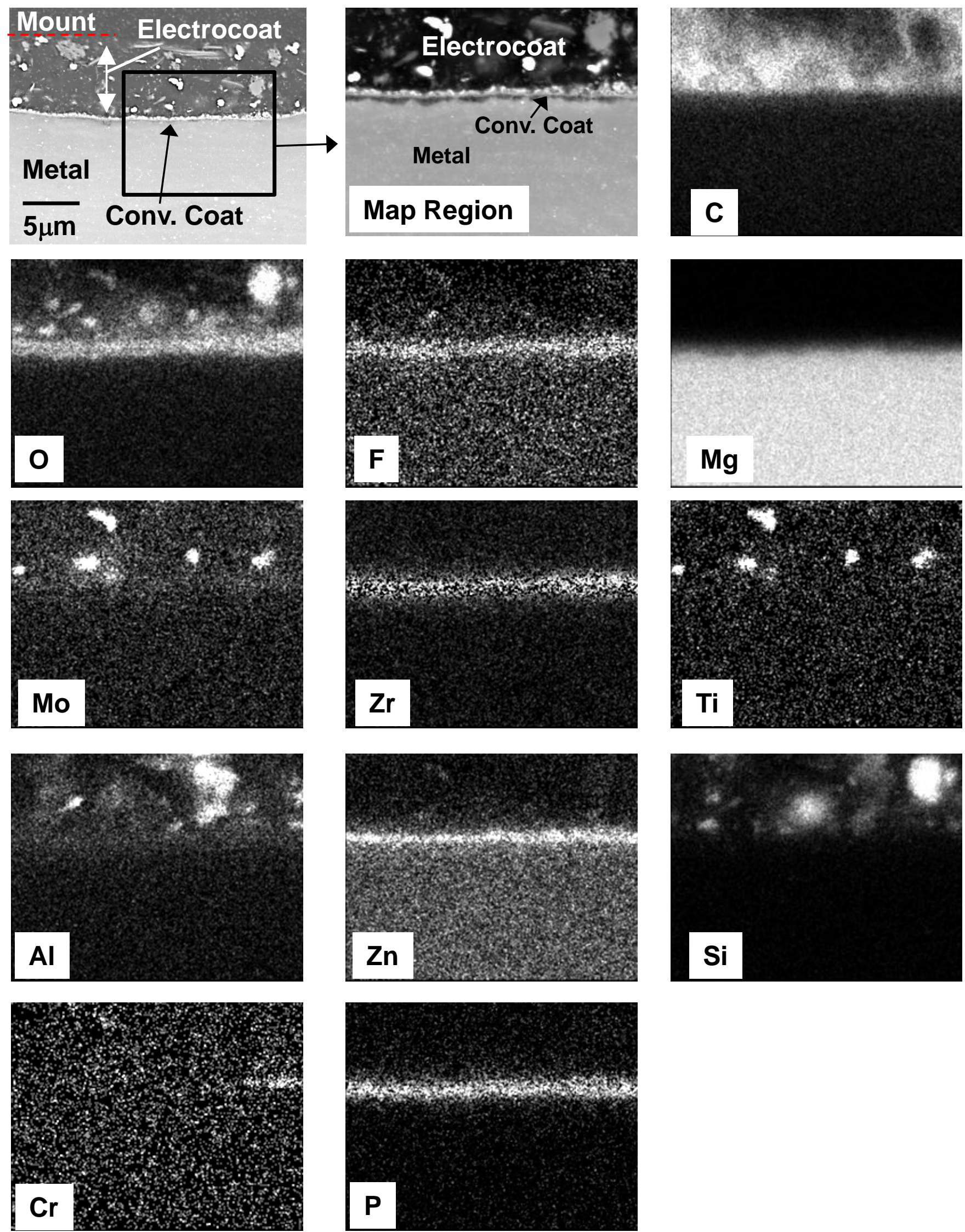

Fig. 7 - Backscatter mode SEM cross-section images and elemental maps of SE7 + electrocoat. 


\section{a) SE7}
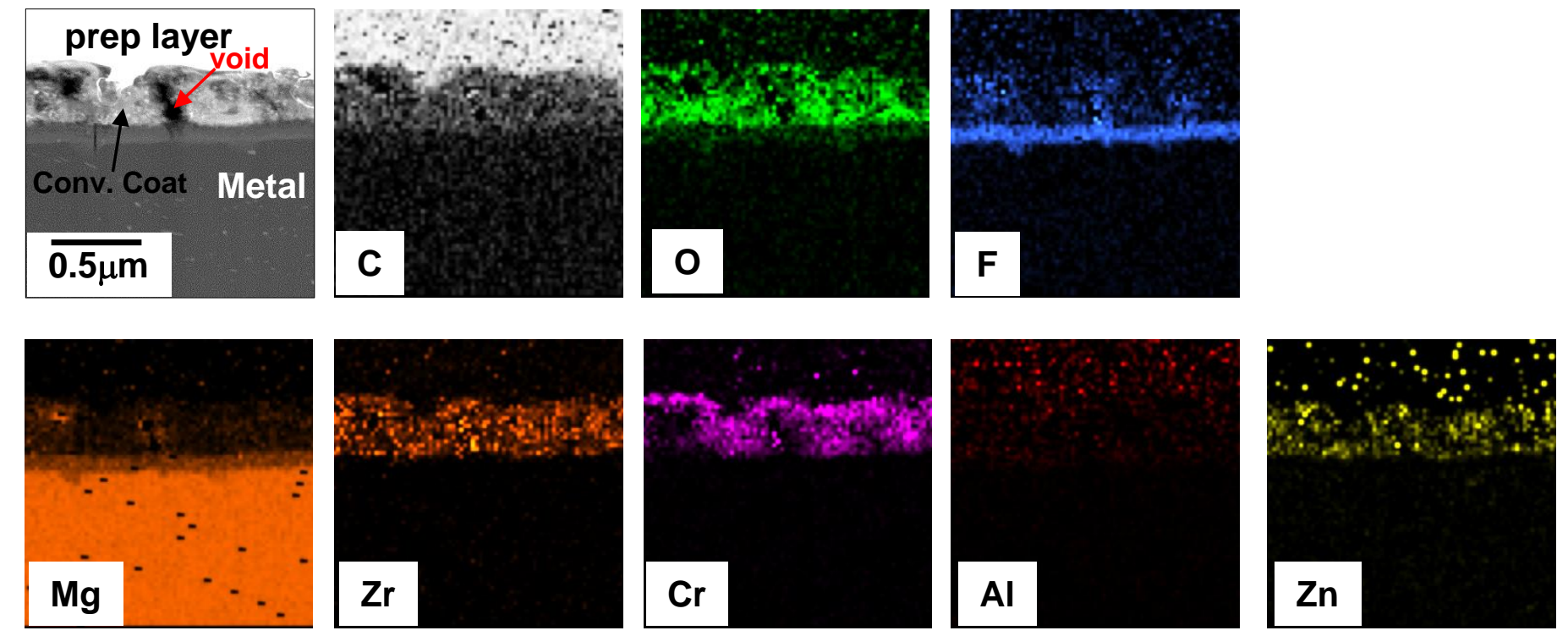

b) SE7 + electrocoat
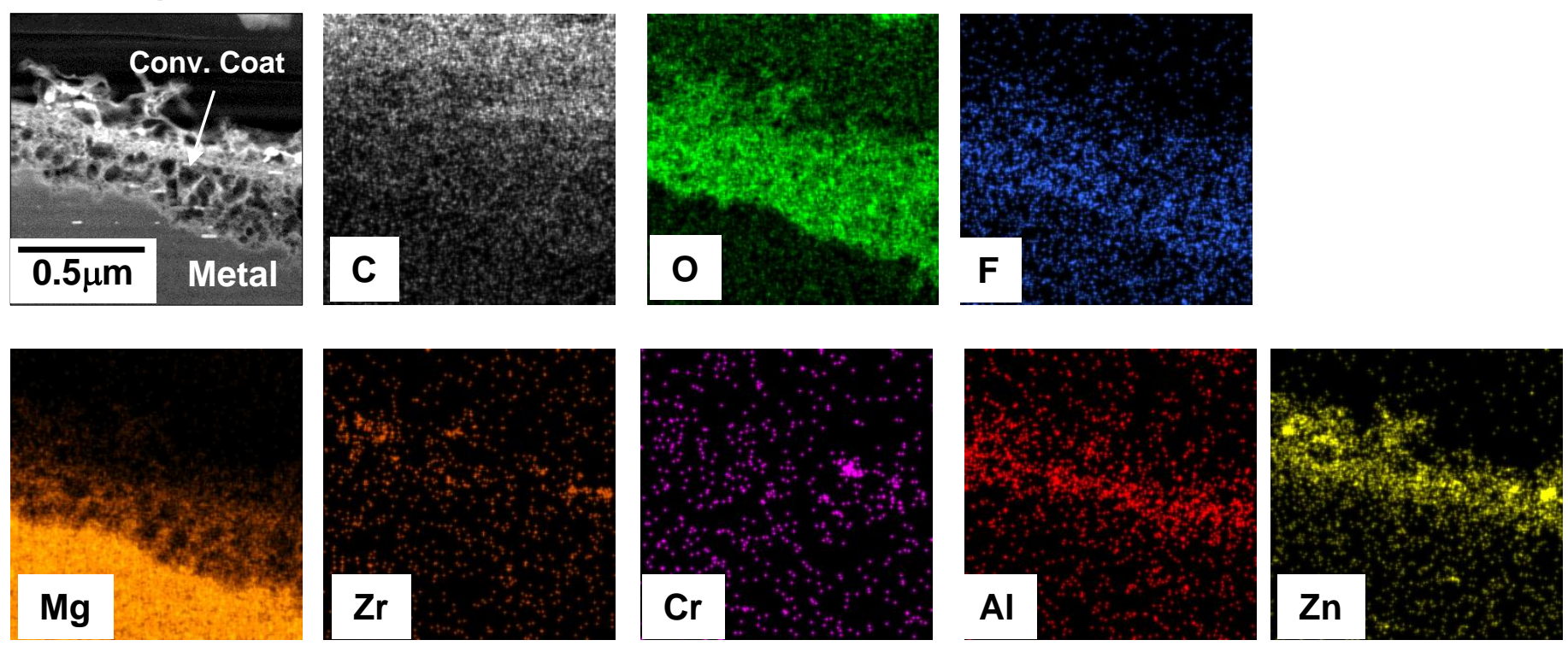

Fig. 11 - Cross-Section dark field STEM images and corresponding elemental maps for as-conversion coated SE7 (a) and the coating-substrate interfacial region after subsequent application of the SE7 + electrocoat. (b) 

a) $B A Z$
b) BE7

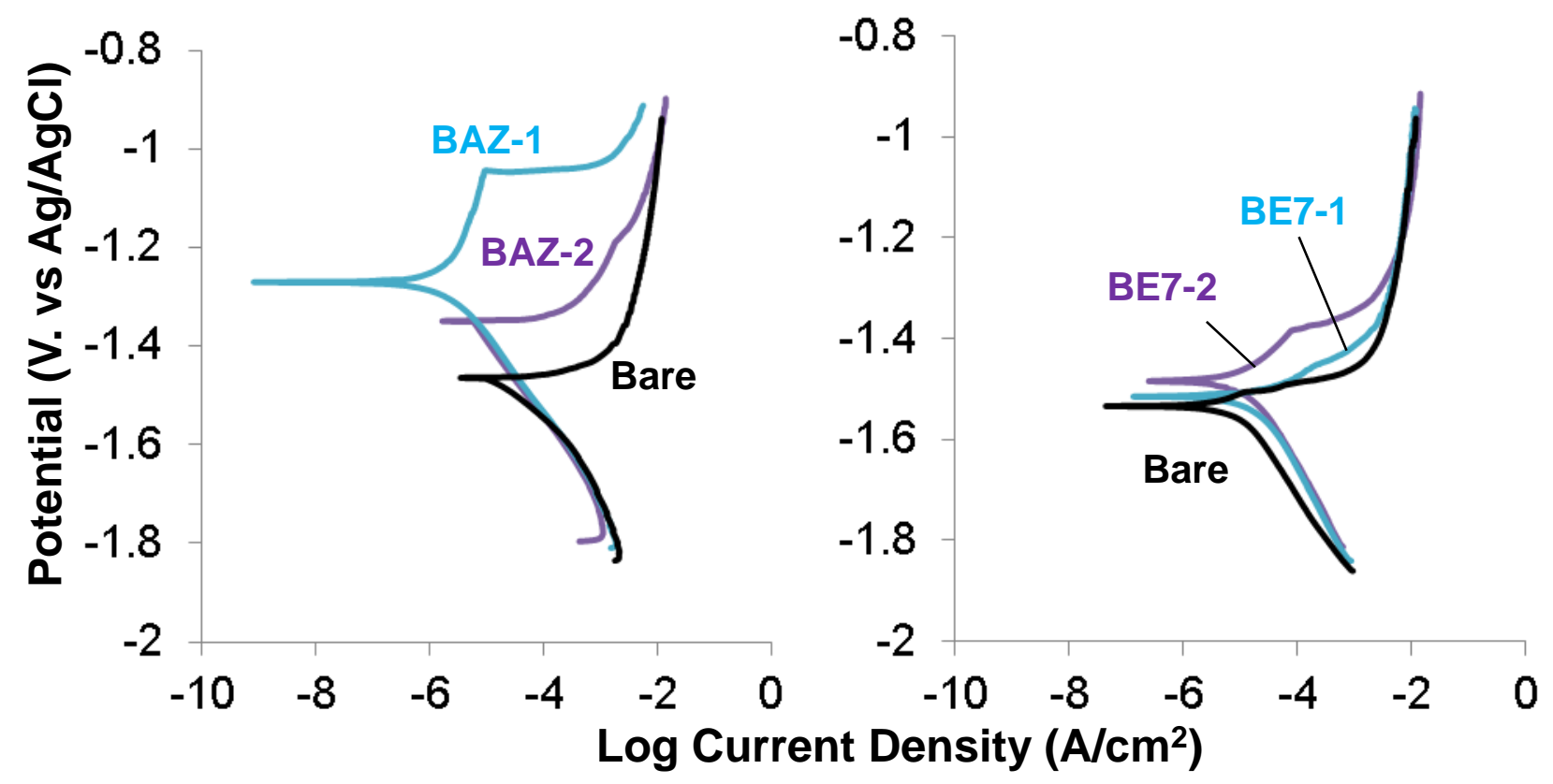

c) $\mathrm{SAZ}$

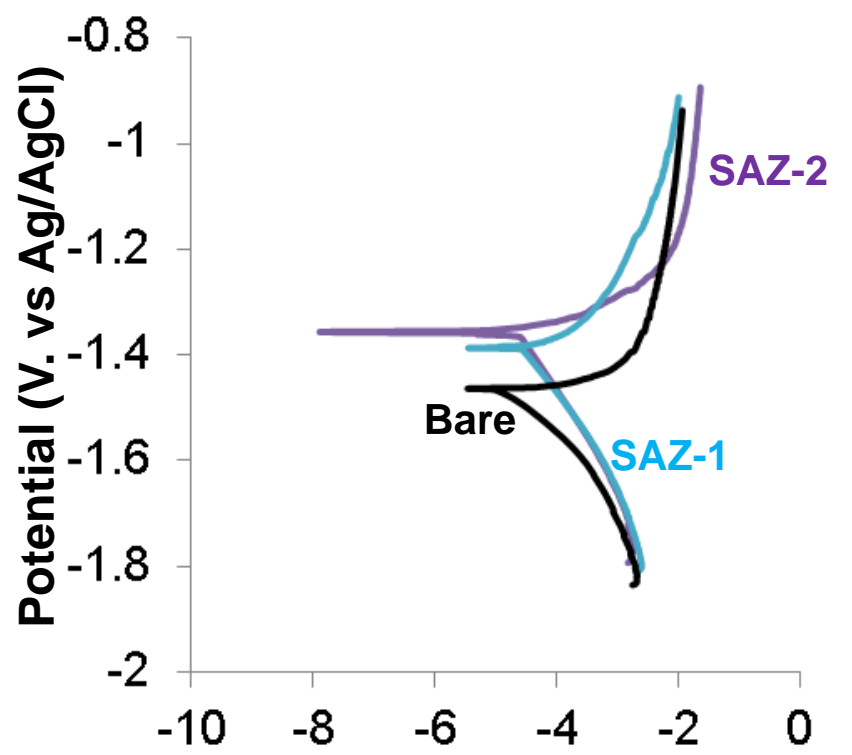

d) SE7

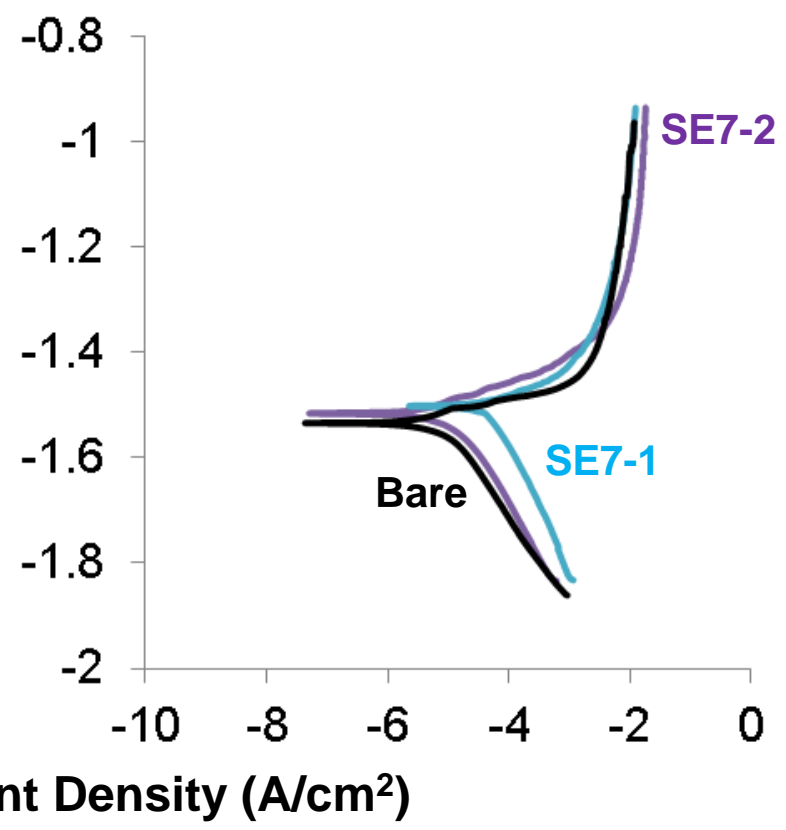

Fig. 12 - Potentiodynamic polarization data for AZ31B and E717 bare and as-conversion coated in saturated $\mathrm{Mg}(\mathrm{OH})_{2}+1$ wt. $\% \mathrm{NaCl}$ at room temperature. 


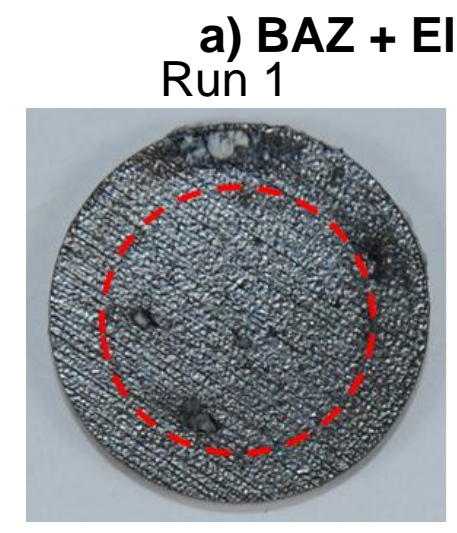

\section{lectrocoat}

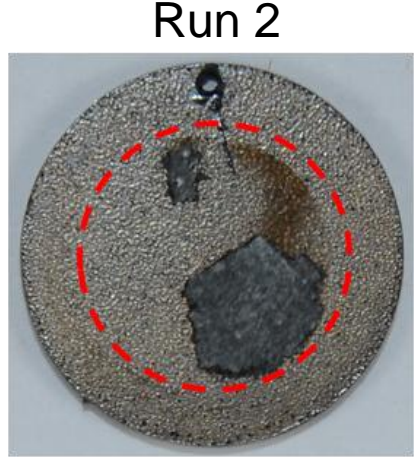

c) $\mathrm{SAZ}+$ Electrocoat

\section{Run 1}

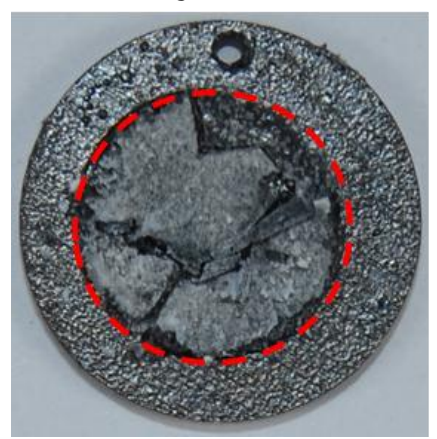

b) BE7 + Electrocoat

Run 1
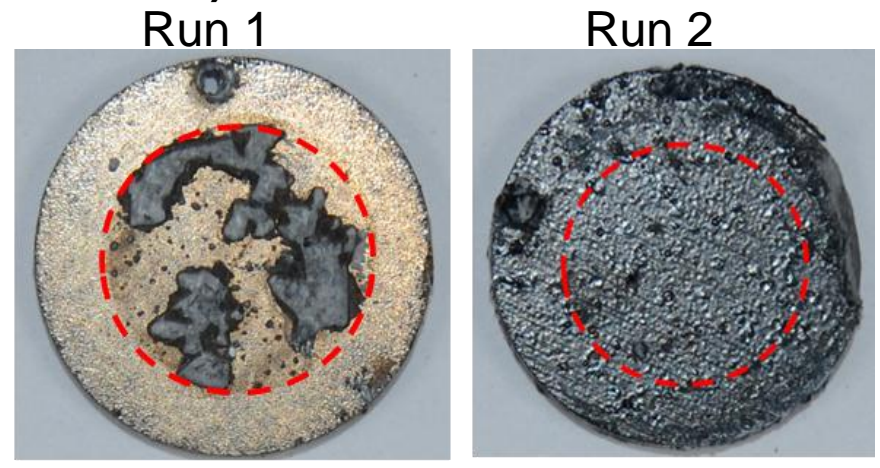

d) SE7 + Electrocoat

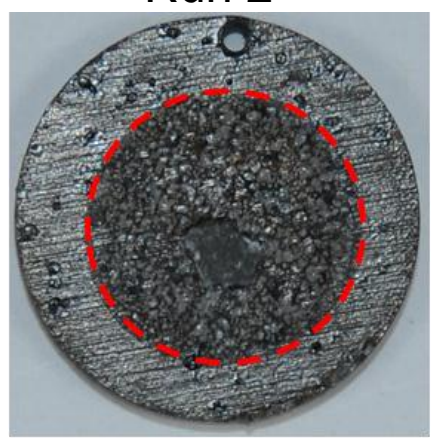

Run 1

Run 2

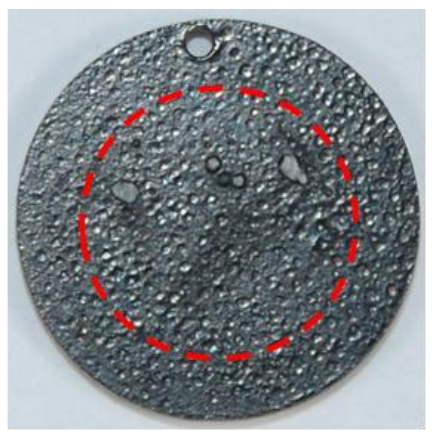

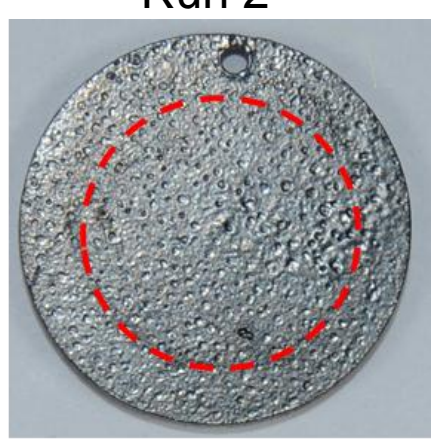

Fig. 13 - Photographs of conversion coated+ electrocoated AZ31B and E717 test samples after corrosion screening of $48 \mathrm{~h}$ immersion in $\mathrm{Mg}(\mathrm{OH})_{2}+1 \mathrm{wt} \% \mathrm{NaCl}$ at room temperature followed by potentiodynamic polarization from $\sim-1.75 \mathrm{~V}$ to $\sim-0.9 \mathrm{~V}$ vs Ag/AgCl (start/finish voltage ranges varied sample run to sample run by $\sim \pm 0.1 \mathrm{~V}$ except for $\mathrm{SAZ}+$ electrocoat run 2 , which started at $-1.45 \mathrm{~V})$. Test samples were $15 \mathrm{~mm}$ diameter, with exposed area of $10 \mathrm{~mm}$ diameter marked by red dashed line (the as-electrocoated surface was black). 